\title{
The Empirical Structure of Narrative Identity: The Initial Big Three
}

\author{
Kate C. McLean ${ }^{1}$, Western Washington University \\ Moin Syed, University of Minnesota \\ Monisha Pasupathi, University of Utah \\ Jonathan M. Adler, Olin College
}

William L. Dunlop, University of California, Riverside

David Drustrup, University of Iowa

Robyn Fivush, Emory University

Matthew E. Graci, Emory University

Jennifer P. Lilgendahl, Haverford College

Jennifer Lodi-Smith, Canisius College

Dan P. McAdams, Northwestern University

Tara McCoy, Monmouth College

In press

Journal of Personality and Social Psychology

\author{
${ }^{1}$ Corresponding Author. Department of Psychology \\ Western Washington University \\ 516 High St., MS 9172 \\ Bellingham, WA 98225 \\ Phone: $360-650-3570$ \\ Fax: 360-650-7305 \\ Email: Kate.McLean@wwu.edu
}

Author Notes. We thank the Foley Center grant to Dan McAdams for the funding of Sample 2, and Gina Logan for managing the project. We thank the following coders: Justin Poh and Sophia Seitz (Olin College); Sammy Loch, Lexi Lowe, Alyssa Goodwin, Kristin Sarjeant, Sierra Combs (Western Washington University); Will Hynes, Misty Coplan, Leith Christensen, Aydin Tasevac, Will Giddings, Mekayla Brooks (University of Utah); Beth Rakowski, Charlotte Bamford, Furon Hilliard, Hatun Almhanna, Helena Mazurek, Helen Capita, Haylie Virginia, Jerrell Lanos, Kayla Markott, Laura Anderson, Melanie Nyhan, Max Rosenthal, Megan Stoll, Rufina Tsur-Tsar, Sara Cunningham, Sara DiMayo, Steve Zafuto (Canisius College). We also thank the following institutions for helping to fund several meetings at which this project was developed: Emory University, The Foley Center at Northwestern University, Haverford College, University of California at Riverside, University of Utah, Western Washington University, Canisius College, Connecticut College, and Olin College. 


\begin{abstract}
A robust empirical literature suggests that individual differences in the thematic and structural aspects of life narratives are associated with and predictive of psychological well-being. However, one limitation of the current field is the multitude of ways of capturing these narrative features, with little attention to overarching dimensions or latent factors of narrative that are responsible for these associations with well-being. In the present study we uncovered a reliable structure that accommodates commonly studied features of life narratives in a large-scale, multiUniversity collaborative effort. Across three large samples of emerging and mid-life adults responding to various narrative prompts ( $N=855$ participants, $N=2565$ narratives), we found support for three factors of life narratives: motivational and affective themes, autobiographical reasoning, and structural aspects. We also identified a "functional" model of these three factors that reveals a reduced set of narrative features that adequately captures each factor. Additionally, motivational and affective themes was the factor most reliably related to well-being. Finally, associations with personality traits were variable by narrative prompt. Overall, the present findings provide a comprehensive and robust model for understanding the empirical structure of narrative identity as it relates to well-being, which offers meaningful theoretical contributions to the literature, and facilitates practical decision making for researchers endeavoring to capture and quantify life narratives.
\end{abstract}

Key Words: Narrative Identity, Life Stories, Well-being, Personality Structure 


\section{The Empirical Structure of Narrative Identity: The Initial Big Three}

Narrative identity matters for some of the most fundamental components of the human condition; perhaps most important, it matters for psychological well-being (see Adler, LodiSmith, Philippe, \& Houle, 2016 for a review). Indeed, individual differences in how stories about one's important experiences are told both reflects current well-being and predicts wellbeing over time (Adler et al., 2016). That said, life narratives ${ }^{1}$ contain a wide array of features, and provide a uniquely generative source of psychological data (e.g., Adler, Dunlop, Fivush, Lilgendahl, Lodi-Smith, McAdams, McLean, Pasupathi, \& Syed, 2017). Not surprisingly, then, researchers have approached the task of quantifying narratives in many ways - from the emotional valence of a story, to its psychological complexity, to the meaning made of a past event, to name but a few. Although that variety has value in showcasing the richness and diversity of the stories that people tell, it can also render it more difficult to capture and replicate foundational phenomena.

The primary goal for the present project was to take an empirical approach to uncovering shared underlying dimensions of a broad range of commonly quantified features of life narratives. There are many ways that researchers capture features of narrative; the ones we focused on, described below, are consistent with theoretical approaches to narrative identity, and have been repeatedly found to be empirically fruitful in the field of personality science. Such an endeavor offers theoretical insight into the structure of these narratives for the study of personality, and practical insight into which distinct narrative features can capture those

\footnotetext{
${ }^{1}$ We use the term "narrative identity" to capture the broad construct represented at the third level of personality (e.g., McAdams \& McLean, 2013; McAdams \& Pals, 2006; Singer, 2004). Throughout the paper we use the term "narrative" or "life narratives" to indicate our focus on narratives that are derived from important episodes in one's life, often key scenes in the life story.
} 
dimensions empirically. A secondary goal of this project was to test links between those underlying dimensions and well-being and personality traits, two sets of variables often explored alongside narrative identity, to understand the role of these dimensions in personality functioning. In short, in looking at a variety of existing quantitative approaches to capturing narrative identity, we examine whether there is empirical support for a common framework that both accommodates distinct features of narrative and shows how they are interrelated. This was an ambitious, large-scale, multi-University collaborative effort, with the overarching goal that the results would not only clarify and organize the existing literature, but also serve as a fulcrum for the direction of the field.

\section{Similarities and Distinctions in the Levels of Personality}

Motivated by the intensive work on the establishment of traits as a fundamental component of personality (see McCrae \& Costa, 2008), over the past three decades substantive theoretical and empirical work has shown that personality is a complex structure of many components beyond traits, which McAdams (1993; 1995; McAdams \& Pals, 2006; but see also DeYoung, 2015) has defined as levels of personality: traits, characteristic adaptations, and narrative identity. This articulation of personality as multi-leveled was revelatory in organizing the dynamic assembly of constructs that make up personality, and in embracing the complexity of understanding the person.

However, researchers have yet to interrogate the structure of the other levels of personality in the way that researchers have done with traits. Indeed, in thinking about how the current endeavor fits with other developments in personality science, we highlight the renaissance of trait research after the comprehensive work on their structure and the establishment of the five-factor model (e.g., Costa \& McCrae, 1994; Goldberg, 1993; John \& 
Srivastava, 1999). Taking a lesson from this historical pivotal development, we see our efforts as sharing some similarities to a search for a Big X for life narratives, as our primary goal was to provide organization to the commonly examined narrative features that have been empirically and theoretically established as fundamental to narrative identity in an attempt to draw some conclusions about how those features are structured.

However, it is also important to observe the distinctions between these levels of personality (see McAdams \& Pals, 2006), distinctions that should be at the forefront in the endeavor to uncover personality structures. Most critically, unlike the focus of the five-factor model, in which researchers argued that language captures all of the important trait terms (see John, Angleitner, \& Ostendorf, 1988), we do not claim to be capturing the complete or final structure of narratives, because there is no evidence that researchers have actually captured all of the important features of life narratives. In fact, by organizing existing approaches to quantifying narrative, our project had two concrete goals: 1) to understand the commonalities and distinctions in the features of narrative identity that have been commonly captured in the extant literature, and 2) to distill the dimensions of what has been captured, making it easier to see what has not been captured in the service of future work.

Thus, we do not claim to be examining an exhaustive array of narrative features and, of course, the factor analytic approach that we took can only uncover dimensions of the variables included (see Block, 1995). However, there is a robust body of work for us to build upon in examining the structure of narrative identity as presently studied, and we drew primarily, though not exclusively, from work done within the field of personality psychology. The narrative features included in this project are those that have been reliably examined in numerous prior studies and are consistent with theoretical approaches in personality. They were also initially 
developed through intensive, inductive, bottom-up strategies based on the ways in which individuals actually narrate their lives. We turn now to a discussion of the narrative level of personality, and the existing theoretical and empirical guidance on what the structure of this level might look like.

\section{Conceptual Perspectives on the Structure of Narrative Identity}

At their heart, the kinds of narratives we are interested in are about identity: the stories we tell about ourselves reveal ourselves, construct ourselves, and sustain ourselves through time (Bruner, 1990; Habermas \& Bluck, 2000; Hammack, 2007; McAdams, 2001; McLean, Pasupathi, \& Pals, 2007; Pasupathi, 2001; Pasupathi, Mansour, \& Brubaker, 2007; Sarbin, 1986; Singer, 2004). Researchers have examined this process of self-authorship through an examination of an array of types of narratives, from the high and low points of our lives, to selfdefining memories and turning points, all of which constitute important moments in our lives and can be fodder for the larger life story. Constructing stories about these memorable and significant events, making meaning of them, linking them together to form a larger life story, and revising them as new information and events arise and as self-understanding develops is a powerful and dynamic mechanism of psychological functioning.

Critically, in recalling a past event it is not the event itself that is central to a personological understanding, it is how the person constructs the event in narrative form (Bruner, 1991; Fivush, 2001; McAdams, 1985; Sarbin, 1986). This means that researchers interested in this subjective construction are tasked with capturing the features of narrative most relevant to psychological functioning. The following is a list of some of the most commonly captured features of life narratives:

agency, communion, valence, redemption, contamination, closure, coherence (at least three kinds), exploratory processing, growth goals, integrative and intrinsic memories, 
positive and negative meaning-making, elaboration, sophistication, accommodative processing, differentiated processing, ending valence, affective processing, intimacy, foreshadowing, complexity (see Adler et al., 2016).

The reader may be overwhelmed by this (partial) list. What is a researcher interested in studying life narratives to do when confronted with all of these ways of quantifying them, and how is the consumer of science to make sense of this variety? For example, do exploratory processing, selfevent connections, and meaning-making share an underlying dimension, or are they distinct constructs?

One approach to the dizzying array of possibilities is to consider the ways in which definitions of the above features of narratives have overlapping conceptual qualities. For example, self-event connections (Pasupathi et al., 2007) and meaning-making (McLean \& Thorne, 2003) both require that the narrator make an explicit link between a past event and current understanding of self (e.g., "Getting divorced helped me to understand that I was stronger than I thought.").

Examining these conceptual overlaps is the approach taken in a recent review of the extant literature (Adler et al., 2016), which included ten experts conceptually grouping narrative features. From this, Adler et al. (2016) derived four constellations of narrative that are especially important to well-being: affective themes, motivational themes, themes of integrative meaning, and structural elements. These factors are also consistent with other approaches to organizing the field at the conceptual level (Habermas \& Bluck, 2000; McAdams \& McLean, 2013), and we review them in turn below.

Affective Themes. The affective component of narrative concerns emotion - either of the narrative in total (e.g., overall tone), or parts of the narrative (e.g., ending valence). Researchers have often examined the emotional trajectory of a narrative, primarily shifts from the beginning 
to the end of a narrative. This is captured by the concepts of redemption (movement from negative to positive), and contamination (movement from positive to negative) (e.g., McAdams, Reynolds, Lewis, Patten, \& Bowman, 2001).

Motivational Themes. The motivational component of narrative captures goal-like orientations about broad-based general life concerns. The most common constructs under this constellation are agency and communion (Bakan, 1966; McAdams, 1993; Wiggins, 1991). The former concerns autonomy and the motivation to impact or influence others or one's life circumstances. The latter captures concerns with interpersonal connection.

Themes of Integrative Meaning. This component captures whether and how much reporters indicate interpretation or reflection in their narration of the event (e.g., Habermas \& Bluck, 2000). We note that this is a category in which there may be the most variety in approaches to quantifying narratives. Indeed, we apply the term autobiographical reasoning (Habermas \& Bluck, 2000) in the present project because it captures a greater range of constructs including meaning-made, the search for meaning or other reflective processes, and connections between events themselves. However, broadly, the function of this reasoning process is to make sense of the important events of one's life, establishing personal temporal continuity (Pasupathi et al., 2007). Individuals may approach this meaning-making task in a variety of ways. For example, assimilative approaches weave new experiences into existing narrative plotlines, whereas accommodative approaches require the substantial revision of one's current self-stories or the creation of new narrative plotlines in order to include new experiences. Further, some events that we experience do not become integrated into our broader sense of self-understanding, and some do; and in order to do that integration, some meaning must be made. 
Structural Elements. The structure of narrative includes aspects such as temporal details, the order of the narrated content, and the degree and complexity of detail needed for audience orientation, often subsumed under the broader label "narrative coherence" (see Adler, Waters, Poh, \& Seitz, 2018; Baerger \& McAdams, 1999; Lysaker, Clements, Plascak-Hallberg, Knipscheer, \& Wright, 2002; Reese, Haden, Baker-Ward, Bauer, Fivush, \& Ornstein, 2012). Relatedly, researchers in cognitive, social and developmental psychology have also examined the elaboration of narratives along factual (observable details) and interpretive (psychological experience) dimensions, based on theoretical distinctions between the landscapes of action and consciousness (Bruner, 1990; Pasupathi \& Hoyt, 2009; Pasupathi \& Wainryb, 2010). Structure can be thought of as an architectural component of narrative, less focused on the personal evaluation or meaning of the event, and more focused on the degree to which the story is elaborated and coherent, or 'makes sense.'

\section{Complexities with these Groupings}

The four categories proposed by Adler and colleagues (2016) were derived inductively, from the perspectives of ten experts in the study of narrative identity. But the underlying empirical basis for these groupings remains unknown. As Adler and colleagues (2016) noted, there may be important overlaps both within and across the proposed categories. For example, Adler et al. (2016) labeled redemption and contamination affective themes, but as they noted, these themes also capture something about structure (e.g., shift in the ordering of emotion), and meaning (e.g., drawing positivity from a negative experience). Adler et al. (2016) settled on these themes as being affective "at their core" (p. 161), and in part, this is because a conceptual grouping had to draw lines between constructs, and the centrality of affect to definitions of redemption and contamination supported their decision. Similarly, agency and communion 
might belong in a separate category of motivational themes, but it is also hard to envision how a strong or weak sense of agency or communion would be effectively conveyed without including some kind of affective tone.

Although the conceptual review provided a strong foundation for organizing the basic elements of narrative identity, such conceptual work requires an empirical examination, which was the aim of the present study. That is, although we see that some features share conceptual overlap (e.g., self-event connections and meaning-making within the theme of integrative meaning), they are rarely used in the same study, so we know little about their empirical overlap. An empirical approach to the structure of life narratives would have significant advantages when considered alongside a conceptual approach. At the most fundamental level, an empirical approach provides quantitative evidence for the nature of the narrative structures that emerge. Further, such an approach allows for more complexity in that structure - as narrative qualities like redemption or contamination can be explicitly examined in relation to more than one underlying dimension (i.e., we can see if they 'load' on more than one dimension, such as affect and meaning). In short, such advances from an empirical approach allow us to move beyond classifications that reflect the thinking of experts, towards quantitative evidence that informs those classifications and the practice of narrative research.

There is one extant paper that has addressed the factor structure of narrative using a broad-based, comprehensive set of codes (Graci, Watts, \& Fivush, 2018; see also Adler et al., 2018, for an analogous but more specifically focused analysis of the factor structure of narrative coherence). This study was limited in its analysis of only one sample and a single prompt of only one type of narrative (a stressful event), given recent evidence that there is variability in narrative features by prompt (sometimes moreso than by person) (e.g., McLean, Pasupathi, 
Greenhoot, \& Fivush, 2016). It was also oriented more towards the stress and coping literature rather than the personality literature as was evident in some of the features chosen to capture (e.g., support-seeking, rumination), but it informs our thinking. Using exploratory structural equation models with a sample of college-going emerging adults, Graci et al. (2018) found evidence for four factors that they termed positive processing, negative processing, integrative meaning, and structure. The positive and negative processing factors captured the emotional intensity of the narratives. Positive processing included features such as increased positive affect and positive self-event connections, and decreased contamination and negative self-event connections. The negative processing factor included features such as increased negative affect, interpretive elaboration, and contamination. The integrative meaning factor included a variety of narrative features such as increased exploration, positive self-event connections, thematic coherence, positive affect, negative self-event connections, and communion. Finally, the structure factor included greater coherence and factual elaboration - implying that it captured the extent to which the narratives provided sufficient information and organization.

These results suggest some consistency with Adler and colleagues' (2016) conceptual groupings, such as the integrative meaning and structural factors. However, it also raised some questions. For example, positive connections loaded on both the integrative meaning and the positive processing factors. While this makes conceptual sense, it also raises questions about whether the cross-loadings are vital to a comprehensive model, or whether an acceptable model could exclude cross-loadings in favor of greater parsimony. Further, this study was limited by the examination of only one sample and, importantly, by the use of only one narrative prompt.

To ameliorate some of these issues, we approached the present project with three improvements. First, we examined the structure of life narratives across three large samples 
(Total $N=855$ participants, 2565 narratives): two samples of undergraduate emerging adults (from three different institutions), and one community sample of mid-life adults. Second, we examined a broad set of prompts, in both interview and written form, which cover much of the territory traditional of the life story approach to personality to determine how robust versus dependent a structure would be in relation to prompt.

Third, we examined two models - what we have termed the 'landscape' and 'functional' models. In the landscape model we allowed for the inter-relations between constructs to capture the full empirical picture of the structure of narrative, and its complexities. This model fundamentally targets a theoretical understanding of the structure of commonly studied narrative features, and it also helps us to understand which narrative features are necessarily part of multiple factors (i.e., allowing cross-loadings). In the functional model, we provide a clean factor structure (i.e., no cross-loadings), with the goal of understanding the parsimonious set of indicators that can yield similar latent factors. Including these two models has value for several reasons. First, there has been essentially no attention in the narrative literature to latent variables that may account for the covariance among constructs. Examining how the latent factors vary or not across different specifications can be informative about the robustness of the model, rather than the model being highly determinant on a specific set of indicators. Second, examining both a broad inclusive model and a reduced model can provide some suggestions for what constructs researchers can code for if they are interested in the latent factors and not the indicators. Given the theoretical groupings and initial efforts towards empirical assessments, we can reasonably hypothesize at least three conceptual groupings that target: affective quality (overall, or distinct positive and negative), integrative meaning, or what we term autobiographical reasoning, and structure. 
In sum, for researchers interested in life narratives as an element of personality, understanding latent structure is fundamental to understanding the phenomenon. And an empirical test of the structure of commonly employed narrative features, using large samples and a set of standard and varied narrative prompts, is a necessary next step for this endeavor. For the broader field of personality, however, understanding the latent structure of these features of life narratives will also benefit our understanding of the relationship between narrative and other aspects of personality and functioning - here we examine associations between well-being and dispositional traits.

\section{The Relation between Narrative Identity and Well-being}

Individual differences in narrative identity have repeatedly demonstrated significant concurrent and prospective associations with well-being (Adler et al., 2016), and change in narrative variables has been shown to precede associated changes in well-being (Adler, 2012). We note at the outset that the literature on well-being is vast and includes an array of concepts and measurements. We employ a relatively broad definition in our review, including literature that addresses both hedonic, eudaimonic, and state and trait aspects of well-being. Due to the samples to which we had access (see Present Study section), we largely examined the hedonic side of well-being in the present paper (e.g., satisfaction with life, positive affect), but we also have some assessments of negative well-being (e.g., negative affect, depression), and health.

Adler et al. (2016) reviewed the extant research on the relation between narrative features and well-being, providing evidence that each of the conceptual groupings is indeed related to well-being and demonstrates incremental validity in the association with and prediction of wellbeing above and beyond other variables such as demographics and dispositional traits. In terms of affect, generally more positive or redemptive narratives are associated with more positive 
well-being, and more negative or contaminated narratives are associated with more negative well-being (e.g., Adler \& Hershfield, 2012; Dunlop \& Tracy, 2013; Lodi-Smith, Geise, Roberts, \& Robins, 2009; McAdams et al., 2001), and there is some evidence of other moderators in the relation between well-being and affective features, such as age (e.g., McLean \& Pals, 2008). At a broad level regarding motivational themes, higher degrees of agency and communion are associated with higher well-being (e.g., Adler, 2012; Philippe, Koestner, Beaulieu-Pelletier, \& Lecours, 2011). Integrative meaning, or autobiographical reasoning, is generally associated with higher well-being, though there are some important caveats including age (e.g., Banks \& Salmon, 2013; McLean, Breen \& Fournier, 2010; Waters \& Fivush, 2015), type of event (e.g., Mansfield, McLean, \& Lilgendahl, 2010), and whether the meaning is accompanied by positive resolution (e.g., Pals, 2006). Similarly, themes of growth, which is autobiographical reasoning resulting in positive self-change, is associated with higher well-being (Bauer, McAdams, \& Sakeda, 2005; Lilgendahl \& McAdams, 2011). In terms of structure, generally more organized, detailed, and elaborated narratives are associated with greater well-being and lesser psychiatric disturbance (e.g., Adler, Chin, Kolisetty, \& Oltmanns, 2012; Baerger \& McAdams, 1999; Lysaker et al., 2002). However, the degree to which the event is highly negative (e.g., Graci et al., 2018) or more closely identity-related (Waters \& Fivush, 2014) also matters.

All of these relations to well-being were found in studies using individual coding systems. For example, there are studies examining exploratory processing or accommodative processing or meaning-making in relation to well-being. The only study to date that has examined the underlying factors of multiple narrative features simultaneously in relation to wellbeing was Graci and colleagues (2018). They found that the positive processing factor was related to lower anxiety overall, and that integrative meaning was related to higher perceived 
growth following the event. In this study of stressful events, the structure factor was related to higher distress levels, which may reflect the idea that there are moderators of the relation between narrative and well-being. For example, a highly organized, structurally sound narrative about a highly stressful event may indicate a high engagement with the experience, which may actually be distressing, or even related to post-traumatic stress disorder (e.g., Boals \& Schuettler, 2010), compared to such a narrative about a turning point experience - though such a possibility was not testable without access to narratives from different prompts. Thus, the findings from Graci and colleagues offer us some clues regarding the relation between the dimensions of narrative and well-being, but they are compromised by an examination of a very specific prompt - narratives of highly stressful events, which may or may not generalize to a broad array of life narrative prompts.

\section{The Relation between Narrative Identity and Personality Traits}

In order to provide a comprehensive analysis of the structure of life narratives, we not only examined relations between features of narrative and well-being, but also relations with dispositional personality traits. Given that narrative identity is posited to be a separate level of personality (McAdams, 1995; McAdams \& Pals, 2006), it becomes useful not only to evaluate the structure of narrative, but also to establish how the structure of the narrative level of personality is interconnected with the structure of the trait level of personality, the most commonly used level in personality research. Prior work has addressed the relations between life narratives and traits in several ways, primarily by demonstrating relations between traits and specific narrative features (our manifest variables). For example, McAdams, Anyidoho, Brown, Huang, Kaplan, and Machado (2004), found associations between trait agreeableness and communion, between trait neuroticism and negative emotional tone, and between trait openness 
and narrative complexity (see also Lilgendahl \& McAdams, 2011). In the present study we examined relations between our larger dimensions and traits (in Samples 2 and 3) to integrate this work into a larger personality framework, and to show both the inter- and in-dependence of these levels.

\section{Present Study}

In the present study we employ a data-driven analysis, guided by existing conceptual work within the field of personality psychology. There are at least two critical questions facing us - one theoretical and one practical. First, what is the structure underlying the many features of life narratives commonly captured in the literature on narrative in personality psychology? For example, which narrative constructs are indicative of autobiographical reasoning, and which are not? Second, given the recent evidence for stability and variability in narrative features by prompt (e.g., McLean et al., 2016), is this structure relatively invariant across prompt? In answering these two primary questions, we also aimed to replicate this structure across three samples, and to examine the relation between the derived factors and well-being and personality traits. Based on the limited prior work we expected to find at least three conceptual groupings representing: affective quality (overall, or distinct positive and negative), autobiographical reasoning, and structure.

We acknowledge that conducting research within the narrative approach is somewhat hampered by the fact that structural modelling requires large samples, which is a challenge for collecting qualitative data. So, to pursue these questions, we used an existing set of three samples, all relatively large for narrative research (combined $N=855$ participants, $N=2565$ narratives). These three samples were distinct in geographic location and age, and format in which narratives were elicited (written and interview). Participants in these samples also 
provided multiple narratives of different types, allowing us to verify a proposed structure across samples and types of prompts.

We note that these are secondary analyses, as all samples were collected for other purposes. However, we contend that making use of such samples is highly beneficial as it reduces burden on participants, encourages collaboration across labs, and increases efficiency. The primary downside is our inability to pre-register our hypotheses, given familiarity with the data.

\section{Methods}

Each of the samples described below were conducted under IRB approval at the following institutions: Sample 1: Western Washington University EX11-018, University of Kansas HSCL \#19268; Sample 2: Northwestern University STU00001801-MODCR0002; Sample 3: Northwestern University Project \# 0341-002. De-identified data files of survey

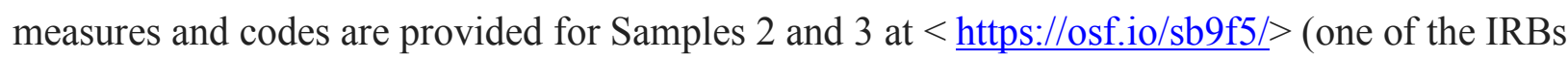
for Sample 1 did not consent to data being made public). We cannot make the narratives publicly available to protect participants identities and anonymity.

We used three existing datasets for the purposes of these studies. That is, each of these datasets were not collected for the present purposes and published analyses of them already exist. No prior publications relying on these three datasets included the kinds of analyses we conducted, or the aims of the current study, except Adler and colleagues (2018), who used the second sample to look specifically at the factor structure of narrative coherence (we include a full list of articles using these data sets on, $<$ https://osf.io/sb9f5 $>$. Each of the samples and associated studies are described below, along with the coding procedures. Because we relied on existing data we did not have control over the sample sizes used in the analyses, but we used 
structural equation modeling and combined samples, when appropriate, to enhance power and the sample sizes are generally adequate to achieve $80 \%$ power for the effects sizes that are typical of individual differences research (Hemphill, 2003). Mundfrom, Shaw, and Ke (2005) conducted simulations that considered the number of factors, ratio of factors to variables, communalities, and level of agreement across models. Mapping our data to match these simulated conditions, the minimum sample size is 200 , which we exceed in all models.

We took a consensus approach to deciding on the most theoretically relevant coding systems to utilize, some of which had been previously coded for the purposes of prior studies. We divided the remaining coding systems to the labs of authors on this paper. Some of the coding systems had been applied to only some of the datasets for prior projects; thus, new coding teams coded remaining datasets for those systems. Some coding systems were newly applied to all of the datasets within one lab. Thus, there is a combination of approaches, given the complexities of using existing datasets. However, in each of the studies we followed the best practice recommendations for narrative research (Adler et al., 2017). Coders included authors on this paper, as well as undergraduate and graduate students. All coding systems and prompts are available on $<$ https://osf.io/sb9f5/>.

\section{Sample 1: Procedure}

The data were collected as part of a study on the relation between the narration of different types of autobiographical events, abuse history, and psychological functioning (Greenhoot, McLean, Wood, \& Yoder, 2013; see also McLean et al., 2016). After providing informed consent, participants wrote their narratives on paper, and then completed survey items on a computer program used for the remainder of the session (written with Media Lab v2008; Empirisoft, 2008). 


\section{Sample 1: Participants}

We recruited 577 participants through psychology subject pools at two large public universities in the Midwest $(n=136)$ and in the Northwest $(n=441)$ of the United States. A small number $(n=25)$ of participants did not complete the narrative portion of the study, leaving an analytic sample of $N=552$ providing a total of 1656 narratives (mean age $=19.5$ years, range $17-29 ; 68 \%$ females). The sample at the mid-western campus was pre-screened for history of abuse; 211 participants, across both samples, reported past exposure to abuse, domestic violence, or sexual trauma. Participants self-reported ethnicity was White (77\%), followed by AfricanAmerican (4\%), Asian American (6\%), Latino/a (3\%), Native American (.3\%), Mixed (5\%), Other (3\%). Once finished, participants were debriefed, given information about available counseling resources, and thanked. Participants were given course credit for participation, which took an average of $1.5-2$ hours.

\section{Sample 1: Narrative Prompts}

Individuals were randomly assigned to write three personal narratives in response to one of five types of prompts: trauma $(n=111)$, transgression $(n=111)$, low point $(n=105)$, selfdefining $(n=114)$, and turning point $(n=111)$. Traumas were defined as the most negative, stressful, or traumatic events of one's life (Greenhoot, Sun, Bunnell, \& Lindboe, 2013). Transgressions were defined as the worst thing one had ever done, which may have resulted in physical or psychological harm to another, and guilt or shame (Mansfield et al., 2010). Low points were described as extremely negative events, which could include emotions such as despair, disillusionment, terror, guilt, or shame (McAdams, 2006a). Self-defining memories were described as highly emotional, representing an enduring theme in one's life, and helping to explain who one is (Singer \& Moffitt, 1991-1992). Turning points were described as episodes in 
which one underwent an important change in self-understanding (McAdams, 2006a). For each prompt, participants were asked to provide details about where they were, whom they were with, what happened, and their reaction and others' (if relevant). Narratives were 187 words on average (range $=3-905 ; s d=111$ ). All narratives were transcribed for coding. After writing narratives participants also completed several assessments that we do not examine here: a memory about abuse, a memory of overcoming a struggle, ratings of memory characteristics, survey items about memory telling, surveys assessing abuse history and Post-Traumatic Stress Disorder, and a demographics form.

\section{Sample 1: Surveys}

The following surveys were used to capture well-being; there was no measure of personality traits in this study.

The Center for Epidemiologic Studies Depression Scale (Radloff, 1977) includes 20 items on the frequency of various symptoms of depression (e.g., "I was bothered by things that don't usually bother me.") with ratings of 1-4 (rarely - most of the time) (alpha $=.90)$.

The Satisfaction With Life Scale (SWLS; Diener, Emmons, Larsen, \& Griffin, 1985) contained 5 items (e.g., "in most ways, my life is close to ideal") rated from 1 to 7 (strongly disagree - strongly agree) $($ alpha $=.87)$.

The Pennebaker Inventory of Limbic Languidness (PILL: Pennebaker, 1982) includes 54 physical symptoms (e.g., insomnia, dizziness), which are rated on a 5-point scale assessing the frequency with each symptom is experienced (never - more than once a week). We employed a summed total of frequency across symptoms for analyses.

The Positive and Negative Affect Scale (PANAS; Watson, Clark, \& Tellegen 1988) includes 30 negative (e.g., frightened, upset) and positive (e.g., happy, energetic), rated on a 5- 
point scale for how participants felt at the moment (not at all - extremely; positive emotions, alpha $=.84$; negative emotions, alpha $=.94)$.

We also included self-reports of student GPA.

\section{Sample 2: Procedure}

The data for the present study came from intensive case studies of late-midlife adults collected as part of a longitudinal study of adult personality development (see McAdams \& Guo, 2015; Manczak, Zapata-Gietl, \& McAdams, 2014). Each participant was individually interviewed for 2 to 3 hours according to a standardized life-story protocol adapted from previous studies of narrative identity, and also completed a series of self-report measures.

\section{Sample 2: Participants}

A total of 158 individuals ( $n=474$ narratives; 63.6\% female, 36.4\% male) ranging in age from 55 to 57 years $($ mean $=56$ years $)$ were recruited from the greater Chicago, Illinois, area by a social-science research firm aiming to generate a nonclinical sample of community adults with a roughly equal split between White and African American individuals (final sample was 55\% White, $43 \%$ as African American, $1 \%$ as interracial, $1 \%$ as "other"). Annual household incomes ranged from under $\$ 25,000$ to more than $\$ 300,000$ (median $=\$ 75,000$ to $\$ 100,000$ ). The majority of the sample was college educated: $5 \%$ received a high school diploma only, $27 \%$ attended some college, $24 \%$ graduated college, and 44\% had some graduate education. Participants were paid $\$ 75$ for the assessment.

\section{Sample 2: Narrative Prompts}

Each participant was individually interviewed by a graduate student or postdoctoral fellow trained to administer the Life Story Interview (McAdams, 2008). The interviewer asked participants to think about their lives as if they were a book or novel, complete with chapters, 
key scenes, characters, and themes. All interviews were audio-recorded and transcribed for coding. The transcripts ranged in total length from 5,050 to 26,176 words $(M=11,647.9, S D=$ 4,028.2). For the purposes of the present study, only the high point, low point, and turning point narratives were used, the latter two of which were the same prompts as used in Sample 1. High points were described as particular moments in the story that stand out because they are so positive. Participants also completed a series of online self-report measures prior to their interviews, including a demographic questionnaire and scales to various components of personality, well-being, physical health, and mental health.

\section{Sample 2: Surveys}

The same Satisfaction with Life Scale (Diener et al., 1985) was used as was used for Samples $1($ alpha $=.84)$.

The 60-item NEO (McCrae \& Costa, 2004) was used to assess the five personality traits, each item rated on a 5-point scale (agreeableness, alpha $=.72$; conscientiousness, alpha $=.85$; extraversion, alpha $=.76$; neuroticism, alpha $=.86$; and openness to experience, alpha $=.76$.).

\section{Sample 3: Procedure}

Data for this study come from McAdams, Bauer, Sakeda, Anyidoho, Machado, MagrinoFailla, White, and Pals (2006). College first-years and seniors attending a private university in Illinois were recruited through posted flyers, advertisements in the campus newspaper, and signup tables located in the Student Union. Students who expressed interest in participating were given a booklet of measures to complete at their leisure and asked to return the booklet within 2 weeks. Pre-testing indicated that the booklet required between 3 and 5 hours of time to complete. After 3 weeks, the experimenters contacted by phone or email those individuals who had not yet returned the booklets and encouraged them to do so. 


\section{Sample 3: Participants}

Participants were 145 college first-years ( $n=435$ narratives) $(44 \%$, age range $18-19)$ and seniors (56\%, age range 18 - 23), who were $74 \%$ female, $70 \%$ white, $19 \%$ Asian American, 5\% African American, 2\% Hispanic, and 5\% other. Each student who eventually completed the measures was paid $\$ 50$ for participating in the first part (Time 1) of the study, which is the time period from which the current data are drawn; we do not detail the longitudinal design here (but see McAdams et al., 2006).

\section{Sample 3: Narrative Prompts}

The Guided Autobiography is a written procedure asking respondents to identify and describe 10 key scenes that stand out as especially vivid or important in "the story of your life." For each of the scenes, the respondent is asked to provide a written account that is at least one to two paragraphs in length. (Some respondents choose to type their responses and insert their own sheets into the booklet.) The instructions explain that each account should describe what happened in the event, when it happened, who was involved, and what the respondent was thinking and feeling. In addition, each account should consider why the respondent has chosen this particular scene to describe: "Why do you think that this is an important event in your life story? What does this event say about who you are, who you were, who you might be, or how you have developed over time?',

The prompts used in the present study included low point and turning points (the same instructions as in Samples 1 and 2), and high points (also used in Sample 2). Narratives averaged 200 words per prompt, and were transcribed for analysis. Participants also completed a sentence-completion test, a list of strivings and life goals, and measures of mood not examined in the present study. 


\section{Sample 3: Surveys}

The same Satisfaction with Life Scale was used as for Samples 1 and $2($ alpha $=.84)$.

The 44-item Big Five Inventory (John \& Srivastava, 1999) was used to assess the five personality traits of extraversion $($ alpha $=.76)$, neuroticism $($ alpha $=.86)$, openness $($ alpha $=$ $.76)$, agreeableness $($ alpha $=.72)$, and conscientiousness $($ alpha $=.85)$. Each item was assessed on a 5-point scale (disagree strongly - agree strongly).

\section{Narrative Coding}

For all coding, teams adhered to the recommendations of Syed and Nelson (2015) for establishing and maintaining reliability. Across systems, reliability was conducted on $10-25 \%$ of narratives, depending on sample size and ease of applying these systems. Coders were trained on a subset of narratives, completed reliability on a different sub-set of narratives, then coded the remaining narratives. Coders met to resolve discrepancies or discuss difficult cases. The coding procedures for each system are described below, along with the reliability coefficients.

Growth. The coding of growth was adapted from several previous studies (Bauer et al., 2005; Lilgendahl \& McAdams, 2011; McLean \& Thorne, 2003; Pals, 2006; Singer, Rexhaj, \& Baddeley, 2007), and captured the extent to which a sense of positive personal growth was described as an outcome of the event narrated. Growth was rated on a four-point scale, and was broadly defined as any kind of positive change, development, new insight or lesson, etc. that enhances the person in some way. A rating of one was given if the narrative displayed no evidence whatsoever of growth. A rating of two to four was given if positive growth was present, with the rating determined by the extent to which growth was elaborated on, conveyed as important, and personally transformative. A rating of two captured some suggestion of growth that was minimally elaborated and not prominently featured in the narrative; a rating of 
three was given if positive growth was clearly present and either elaborated or emphasized as important or transformative; a rating of four was given if growth was an elaborated theme of the narrative and the growth described was clearly conveyed as important and transformative (intraclass correlations, ICCs, range from .73 - .77 across datasets).

Exploratory Processing. Exploratory processing (Pals, 2006) was defined as the extent to which a person openly analyzes and explores the meaning of past events in order to understand their internal impact and potential to change the self. Several qualities may contribute to the assessment of the extent to which exploratory processing is evident in a narrative, including explicit reflection on and analysis of the internal thoughts and feelings surrounding the event, description of responses to the event that are encouraging of exploration (discussion with others, acknowledgement of extended reflection, questioning, etc.), complexity of narrative form that includes a consideration of opposing or varied possibilities or juxtaposition of contrasting ideas, acknowledgement of uncertainty and ambiguity, explicit efforts to examine or understand how oneself has been changed by the event, or an acknowledgement of a different vantage in the present than in the past. Exploratory processing was rated on a four-point scale, with 1 being minimally exploratory and four being highly exploratory, as evidenced by the narrative being exploratory in both style and content, with several indicators of exploration present and exploratory processing being a central theme of the narrative (ICCs range from $.71-.81$ across datasets).

Meaning-making. Meaning is defined as the degree to which the participant narrates selfknowledge derived from reflecting on the past experience (e.g., learning lessons, gaining insights), which directs behavior, or changes thoughts or understanding of self, other, or one's worldview (McLean \& Pratt, 2006). Narratives was coded on a four-point scale. A zero 
indicated no explanation of the meaning of the event. Narratives were scored as one if there was a specific lesson that the reporter learned from the event. A score of two was assigned to narratives that contained vague meaning; narratives of this sort describe some growth or change in the self, but the specifics of the change are not clear. Narratives were scored as three if there was evidence that the reporter gleaned specific insight from the event that applies to broader areas of the reporter's life (ICCs range from $.73-1.00$ across datasets).

Self-event Connections. Each narrative was coded for the presence of absence of four types of self-event connections (see Pasupathi et al., 2007). Explain/illustrate was defined as connection that illustrates an existing trait or quality of self. Discount was defined as a connection that defines the self by what he or she normally does, in reference to something atypical. Induce is a connection in which a change in the self was caused by the event. Reveal is a connection is when an experience brings to light a previously unknown aspect of self. Due to low base rates, and consistent with other studies (Pasupathi et al., 2007), explain/illustrate and discount were summed together to capture stability connections, and induce and reveal were summed together to capture change connections. Given that each narrative could be coded as having more than one connection, percent agreement is reported (and was calculated per connection type) and ranged from $76 \%$ - $82 \%$ across datasets.

Elaboration of Facts and Interpretations. Facts are statements in narratives that can be objectively verified. Therefore, factual statements capture something that can be sensed with one of the five senses. They are broken down into statements of action, description, causal information, emotional behaviors, and quotes. Interpretations are statements in narratives that refer to mental processes and subjective interpretations that cannot be objectively verified. Interpretations can be broken down into statements describing emotions, evaluations, goals, 
thoughts, and personal judgments. Narratives were coded on a 0 (complete absence of fact/interpretation) to three (rich factual detail that transports the reader to the event/rich detail about motivations, intentions, and internal states that offer insight into the narrator's mind) scale for facts and interpretations (ICCs range from .73 - .80 across datasets) (adapted from Pasupathi \& Hoyt, 2009).

Coherence. The coherence of the narratives was evaluated with a coding scheme developed by Reese et al. (2012). This scheme allows identification of three dimensions of coherence on a scale of zero (complete absence of the dimension) to three (fully coherent use of the dimension). The dimensions are: context which places the event in time and location; chronology, the degree to which the narrative is temporally organized; and theme, which assesses the clarity of topic in the narrative (ICCs range from $.80-.95$ across datasets).

Affective tone. Affective tone captures the overall emotional tone of narratives ${ }^{2}$. This coding system relies upon a five-point ranging from one (very negative or pessimistic) to five (very positive or optimistic). A score of three indicates a neutral emotional tone. Coders were instructed to consider the entire narrative when formulating their codes. For example, a story that was largely emotionally neutral but concluded positively would not be considered "very positive or optimistic" (ICCs range from .71 - .91 across datasets).

Ending Valence. Adapted from coding for positive resolution (Pals, 2006), the valence of the ending of the narrative was coded using a five-point scale (from very negative to very positive). Coders were instructed to focus on the emotional and evaluative tone conveyed in how the participant concluded the narrative, independent of the objective circumstances of the event.

\footnotetext{
${ }^{2}$ Note that some researchers code affective tone on two dimensions, positive and negative, or examine specific emotions, an approach that may be important for certain research questions.
} 
Narratives that ended on a clearly positive note received ratings of four or five, with a four expressing clear positivity that was mild to moderate in nature and a five expressing clear and strong emotional positivity. Likewise, narratives that ended on a negative note received ratings of one or two, with a two expressing clear negativity that was mild to moderate in nature and a one expressing strong emotional negativity. Narratives that ended more neutrally or in an ambiguous or mixed tone received a rating of three (ICCs range from $=.86-.90$ across datasets). Redemption and Contamination. Redemption is defined as a narrative that begins in a negative state (e.g., loss, illness, divorce), and ends in a positive state (e.g., health, recovery, insights gained). Contamination is the reverse - the story begins in a positive or neutral state, and ends in a negative state. This coding system was applied in two different ways. For Sample one, each narrative was coded for the affective valence of the beginning and the end of the story, with one representing a negative affective state, a two capturing a neutral or mixed state, and a three representing a positive state (McAdams et al., 2001; McLean \& Pratt, 2006) (ICCs range from $.74-.87$ across datasets). From these beginning and end codes, redemption was categorized as moving from a one to two, one to two or three, or two to a three. Contamination was coded with a movement from three to two, three to one, or two to one. For Samples two and three, codes were categorical, with narratives coded as redemptive, contaminative, or neither (kappa= $.71)$.

Agency and Communion. Narratives high in agency are fundamentally concerned with the autonomy of the protagonist. Highly agentic narratives describe protagonists who can affect their own lives (Lysaker et al., 2002), initiate changes on their own (Adler, Skalina, \& McAdams, 2008), and who achieve some degree of control over the course of their experiences. This theme is only coded only as it pertains to the protagonist of the narrative, not other characters. It is 
coded on a zero (protagonists are powerless, at mercy of circumstances) to four (protagonists are able to affect their own lives, initiate changes on their own, and achieves some degree of control over the course of their experiences) (ICCs ranged from .77- .84 across datasets). Narratives are high in communion are fundamentally concerned with the connection, intimacy, love, belonging, union, friendship, and caring of the protagonist. Highly communal narratives describe protagonists who experience satisfying romantic and friendship relationships, involve nurture and caretaking, and are rich with themes of unity and togetherness (McAdams, 1993). Communion is scored on a zero (protagonists are completely disconnected, isolated, or rejected) to four (protagonists are highly connected to others and rich connection language is predominant) (ICCs ranged from .78 - .84 across datasets).

\section{Results}

\section{Analytic Plan}

The first step in the analysis was to determine the optimal factor structure. To do so, we began with a parallel analysis within exploratory factor analysis (EFA) using a geomin (oblique) rotation in Mplus 7.1 (Muthén \& Muthén, 2010). Parallel analysis has been identified as a stronger alternative for factor identification, as the Kaiser criterion (Eigenvalues $>1.0$ ) often over-extracts factors and the scree plot can be difficult to interpret (O’Connor, 2000). Parallel analysis determines the number of factors that would be identified using a random dataset with the same number of variables and cases as the target dataset. This number of factors is set at as the threshold from which to determine the number of factors to extract in the target dataset. This initial parallel analysis was conducted using Sample 1, Memory 1 because it consists of a relatively large sample of participants responding to five different narratives prompts, and therefore the analysis is less likely to be affected by any potential idiosyncrasies associated with 
a single prompt. The weighted least squares estimator (WLSMV) was used for all analyses because of the mixture of categorical and continuous variables in the analysis.

Following the parallel analysis, we conducted an EFA using exploratory structural equation modeling (ESEM), comparing the target factor solution to other potential specifications. In examining the target solution, we set the lower-bound communality $(1-$ estimated residual variance) threshold to .20 , aligning with the goals of the project to broadly capture the interrelations among narrative constructs. Any variable with a communality lower than .20 was removed from the analysis and the ESEM was re-run. This process was conducted iteratively until all communalities exceeded .20. With each re-analysis we examined the scree plot to ensure no deviations from the results on the initial parallel analysis. Once the variables for inclusion were determined, we examined and interpreted the rotated factor solution. To balance inclusion and parsimony, we a priori determined that factor loadings of .30, consistent with empirical observations of a large effect (Hemphill, 2003), would be interpreted as loading on that respective factor, including any cross-loadings.

The next step was to move to a confirmatory factor analytic (CFA) framework. First, we conducted a CFA on the same Sample 1, Memory 1 based on the previously determined solution, setting all factor loadings $<.30$ to zero. This model served as our baseline model that was then fit to the remaining datasets, as described in further detail below. With regard to fit statistics, we report the model chi-square, CFI, and RMSEA based on the specified model. That is, we did not use a data-driven "model-overfitting" approach that relies on modification indices in order to reach some arbitrary benchmarks. Nevertheless, we generally expected a good fitting model to be consistent with standards in the field, specifically a CFI $>.90$ and RMSEA $<.08$, recognizing 
that model fit tends to be lower than these standards in personality assessment using CFAs, particularly when not relying on modification indices (Hopwood \& Donnellan, 2010).

The aforementioned factor analytic procedure was used to determine what we call a "landscape model;" that is, a model that most suitably accounts for the landscape of the narrative constructs included in the study, embracing the complexities of the inter-relations of constructs. However, we were also interested in identifying a "functional model," one that would consist of a reduced set of constructs with a relatively clean factor structure. The utility of this model is that it assesses the robustness of the latent variables across different specifications and it identifies a more parsimonious model that could potentially guide future researchers on which narrative constructs would be most worthwhile to code for, given that coding for a very large number of constructs can be quite burdensome.

Finally, using structural equation model (SEM) we examined and compared how the landscape model and functional model were associated with well-being, distress, and personality traits. Because the inclusion of these additional variables was not consistent across datasets, there are some variations across models, as described in more detail below.

Descriptives and bivariate correlations for all variables can be found in Tables 1 - 5 .

\section{Landscape Model: Exploratory Factor Analysis}

Parallel analysis of Sample 1, Memory 1 clearly indicated three factors should be extracted. Moving to the EFA using ESEM, the three-factor model was a good fit to the data (Table 6, Model 1). Examination of communalities indicated that the stability connections variable was very low, .06. This low communality is consistent with the patterns of loadings for stability connections: -.17 was highest loading, below our a priori threshold of $|.30|$. 
Despite the parallel analysis clearly indicating three factors, and the good fit of the threefactor model, we also examined the two-factor and four-factor models. The two-factor model also fit the data reasonably well, $\chi^{2}(89)=474.25, p<.001, \mathrm{CFI}=.90, \mathrm{RMSEA}=.09(.08, .10)$, although quite a bit worse than the three-factor model. Stability connections continued to have a low communality (.03) and was joined by context coherence (.04), chronological coherence (.04), and facts (.02). Additionally, there were multiple very high cross-loadings. Taken together, the two-factor model was not a viable alternative to the three-factor model.

The four-factor model also had a good fit to the data, $\chi^{2}(62)=139.19, p<.001, \mathrm{CFI}=$ .98, RMSEA $=.05(.04, .06)$, and indeed fit the data better than the three-factor model. All communalities exceeded the .20 threshold, but the pattern of factor loadings indicated the a) stability connections and change connections formed a "bloated specific" factor of their own and b) there was a large number of cross-loadings. Accordingly, we determined that moving forward with the three-factor solution and dropping stability connections from the model was the most defensible action.

Consistent with our planned procedure, we re-ran the ESEM model and again inspected the communalities. All values exceeded .20 and this model fit the data well (Table 6, Model 2). All primary loadings exceeded the pre-specified .30 threshold and we also retained several crossloadings that exceeded .30 . Two of the three factors were readily interpretable and consistent with past theoretical and empirical work. The first factor, which we labeled autobiographical reasoning, consisted of primary loadings from thematic coherence, interpretations, exploratory processing, meaning, change connections, and growth. The second factor, which we labeled structure, consisted of primary loadings from facts, contextual coherence, and chronological coherence. The primary loadings on the third factor consisted of a mix of motivational themes 
(agency and communion) and affective themes (redemption, contamination, tone, and ending valence), which were considered theoretically distinct by Adler et al. (2016). Recall that that we evaluated a four-factor model, and even in that model these two sets hung together. Thus, empirically these two thematic elements appear to be associated with the same latent construct, which we labeled motivational and affective themes.

In this landscape model we also allowed several variables to load on secondary factors. Two variables, ending valence and redemption, had secondary loadings on the autobiographical reasoning factor. Two variables, thematic coherence and interpretations, also had secondary loadings on the structure factor. Finally, growth had a secondary loading on motivational and affective themes.

As a final step to the exploratory factor analytic phase, we re-ran this ESEM model as a CFA using the same data, setting all loadings $<.30$ in the ESEM to zero. This reduced model fit the data well (Table 6, Model 3), although not surprisingly it fit worse than the ESEM model with all loadings included $\left(\Delta \chi^{2}(19)=60.826, p<.001, \Delta \mathrm{CFA}=.011\right)$. Given that this more restrictive model still fit the data very well, this model served as our baseline "landscape model" that was subject to test in the CFA phase. This model is depicted in Figure 1 and all loadings are indicated in Table 7, Model 3.

\section{Landscape Model: Confirmatory Factor Analysis}

The baseline landscape model was fit to four additional data sets. Sample 1, Memory 2 and Sample 1, Memory 3 were the subsequent narratives provided by the same participants as Sample 1, Memory 1. Both of these models fit the data well (Table 6, Model 4 and 5). Moreover, the pattern of loadings was reasonably consistent with the baseline model (Table 7, Model 4 and 5). 
The next two CFA models were applied to the Sample 2 and Sample 3 datasets. Because the samples sizes for these datasets was smaller compared to Sample 1, we ran the analyses after combining the three narratives provided by each person into a single dataset, separately for Sample 2 and Sample 3. Arranged in this way the datasets now include a nested structure- three narratives provided by each person - and therefore the model specification had to be modified.

The optimal analysis in this case would be to conduct a multi-level CFA, fitting the model at both the between (i.e., person) and within (i.e., narrative) levels. However, in the current datasets the sample sizes for both the between and within levels are much smaller than what is typically found in the literature, raising questions about the appropriateness of such an analysis (see review by Kim, Dedrick, Cao, \& Ferron, 2016). Accordingly, rather than fitting a full multi-level CFA we used the sandwich estimator (Kauermann \& Carroll, 2001), which is appropriate when seeking to properly adjust the standard errors due to the nesting. Thus, this model accounts for the nested structure of the data but does not test the generality of the model across the hierarchical structure of the data. These models fit both the Sample 2 (Table 6, Model 6) and Sample 3 (Table 6, Model 7) data well. In sum, the evidence suggests that the factor structure of the landscape model is replicable and robust.

\section{Functional Model: Simplified three-factor model with no cross-loading variables}

The next series of models tested the "functional model" in which all variables that demonstrated cross-loadings in the landscape model were dropped from the analysis. Thus, ending valence, redemption, thematic coherence, interpretations, and growth were all removed completely from the model. Removal of these variables is not to suggest that they are unimportant (see discussion), rather the goal of producing the functional model was to identify a model with a clean factor structure that did not include any cross-loading. This resulted in a 
greatly simplified model, represented by Figure 2. This model was a good fit to Sample 1, Memories 1-3 (Table 6, Models 8-10).

We again used the sandwich estimator to handling the nesting in the Sample 2 and Sample 3 datasets. These models fit both the Sample 2 (Table 6, Model 11) and Sample 3 (Table 6, Model 12) data well, with similar loadings. Thus, as with the landscape model, this reduced functional model was replicable and robust.

\section{Prompt-specific Models}

The preceding models were all conducted on datasets consisting of a variety of narrative prompts. Next, we examined the generality of the model by applying it to specific prompts. For Sample 1, this resulted in three narratives per person, and so we again used the sandwich estimator to account for the nested structure of the data. The Sample 2 and Sample 3 datasets were too small to test individually, but the two datasets consisted of the same three prompts (high points, low points, and turning points), so we combined the two datasets to fit models for each prompt.

For the landscape model, fit for the Sample 1 was reasonable but not optimal based on the CFI but much stronger based on the RMSEA (Table 6, Models 13-17). The patterns of loadings varied somewhat from prompt to prompt but were reasonably consistent (Table 7, Models 13-17). For the Sample 2 and Sample 3, the fit was stronger for low points and turning points, but the model would not converge for high point memories (Table 6, Models 18-20). One immediately obvious problem with the specification of the high point model was the inclusion of contamination, which does not make theoretical sense nor was it empirically observed (i.e., frequency was extremely low). Thus, we removed contamination from the model and re-ran the CFA. This model yielded acceptable fit on par with the other two models from these datasets 
(Table 6, Model 18a). The pattern of loadings across prompts (Table 7, Models 18-20) indicate consistency in all cases except for high points, for which several of the loadings (valence, interpretations, redemption, tone, communion, and growth) were much smaller compared to the other models in Samples 2+3 and Sample 1.

For the functional model, all Sample 1 models demonstrated good fit for self-defining memories, turning point memories, and trauma memories, and less good but still reasonable fit for low-point memories and transgression memories (Table 6, Models 21-25). All factor loadings were generally consistent across models other than contamination, which was more variable (Table 8, Models 21-25).

The Sample 2 and Sample 3 datasets indicated good fit for low point memories and turning point memories, but similar to the landscape model, the model would not converge for high point memories (Table 6, Models 26-28). Once again, we removed contamination and reran the model, but this model also had problems, specifically with agency. Within this set of high point memories, agency did not cohere with communion or affective tone as it did in all of the other models. Indeed, removing agency from the model led to a good fitting model, $\chi^{2}(17)=$ $26.814, p=.06, \mathrm{CFI}=.97, \mathrm{RMSEA}=.04(.00, .07)$. Factor loadings across models were generally consistent, but again the loading for contamination varied (Table 8, Models 26-28). These analyses raise some issues regarding use of prompt-specific models, a point to which we return in the Discussion.

\section{Relations to Well-being and Personality Traits}

In the next set of analyses, we examine how both the landscape and functional models were associated with indicators of well-being, psychological distress, and personality traits, all of which are commonly investigated correlates of life narratives. 
The nature of the data constrained these analyses to only examining the Sample 1 data separately by memory (i.e., separate models for Memory 1, 2, and 3) and the Sample 2 and Sample 3 datasets collapsed together and then analyzed separately by prompt (i.e., high point, low point, turning point). Although there were common well-being and trait data in the Sample 2 and Sample 3, datasets that allowed for combined models, satisfaction with life was the only variable that overlapped with the Sample 1 data. The Sample 1 dataset included multiple measures of well-being and distress, as well as a measure of GPA, whereas the Sample 2 and Sample 3 datasets contained only big five personality traits and satisfaction with life. All models were run in a structural equation modeling framework, with the narrative variables retained as latent variables, as specified in the CFAs, and the outcomes as either latent or manifest variables, as indicated below. Within each target memory all associations were tested in a single model.

In the Sample 1 analyses we first specified a model in which the three latent narrative variables predicted GPA and a latent well-being construct, with SWL, PA, NA, depressive symptoms, and PILL as indicators. Across all six models (three memories x two CFA specifications; landscape and functional) the only statistically significant association was that greater levels of motivational and affective themes was associated with higher latent well-being. This association was detected in all models, and the magnitude of the association was highly consistent: for Memory $1, \beta=.37$ in the landscape model and $\beta=.39$ in the functional model; Memory $2, \beta=.27$ (landscape) and $\beta=.29$ (functional); Memory $3, \beta=.29$ (landscape) and $\beta=$ .24 (functional). All other associations were of small magnitude and not statistically significant (see Tables 9 and 10 for all estimates).

Next, we re-ran the Sample 1 models with the latent well-being construct disaggregated into separate manifest indicators. This was a useful analysis because many of these specific 
measures are used in narrative studies, and so it is informative to identify specific reliable associations. As in the other model, there were no associations with GPA. We present the wellbeing results below separately by measure (see Tables 11 and 12 for all estimates).

Higher levels of depressive symptoms were associated with greater autobiographical reasoning only in the Memory 1 landscape model $(\beta=.11)$. Although not statistically significant, the magnitude was similar for the Memory 1 functional model $(\beta=.09, \mathrm{p}=.10)$. Mirroring the latent well-being models, greater levels of motivational and affective themes was statistically significantly related to lower depressive symptoms in four of the six models: Memory 1 landscape $(\beta=-.21)$ and functional $(\beta=-.23)$, and Memory 2 landscape $(\beta=-.12)$ and functional $(\beta=-.13)$. The associations were in the same direction in Memory 3 landscape $(\beta=-.09)$ and functional $(\beta=-.08)$, but reduced in magnitude.

Higher levels of PILL there were associated with greater autobiographical reasoning only in the Memory 3 landscape model $(\beta=.12)$. Although not statistically significant, the magnitude was similar for the Memory 3 functional model $(\beta=.08, p=.16)$. Higher levels of PILL were also associated with greater levels of structure in Memory 3 landscape $(\beta=.17)$ and functional $(\beta$ $=.15$ ). Finally, higher PILL was statistically associated with lower motivational and affective themes only for the Memory 1 landscape $(\beta=-.14)$ and functional $(\beta=-.14)$ models.

Greater positive affect was associated with greater autobiographical reasoning in the Memory 3 landscape model $(\beta=.13)$, which was attenuated and non-significant in the functional model $(\beta=.08, p=.16)$. In Memory 3 higher positive affect was associated with lower structure, both in the landscape $(\beta=-.11)$ and functional $(\beta=-.12)$ models. Finally, greater positive affect was statistically associated with higher levels of motivational and affective themes across all six models $(\beta s=.17$ to .25$)$. 
For negative affect, the only associations observed were the consistent negative association with motivational and affective themes across all six models ( $\beta \mathrm{s}=-.23$ to -.31 ); higher levels of negative affect were related to lower levels of motivational and affective themes.

Results were similar for satisfaction with life, with positive association with motivational and affective themes in Memory 1 and 2 landscape and functional models ( $\beta \mathrm{s}=.16$ to .24 ), whereas these associations were much smaller in the Memory 3 landscape and functional models $(\beta=.06$ for each).

In the Sample 2 and Sample 3 analyses there were far fewer significant associations, with none consistent across all models (Tables 13 and 14). This could be expected, as these models are prompt specific whereas the Sample 1 models aggregate across multiple prompts. Indeed, the most associations were found for the high point models, where the structure factor was positively associated with satisfaction with life in both the landscape and functional models $(\beta \mathrm{s}=.21$ and .20). In the high point landscape model only, motivational and affective themes was positively associated with agreeableness $(\beta=.35)$, and only marginally so for conscientiousness $(\beta=.19, p$ $=.06)$, and extraversion $(\beta=.19, p=.05)$. For low points, autobiographical reasoning was associated with agreeableness $(\beta=.14)$ and openness $(\beta=.16)$, but only in the landscape model (associations were similar but reduced in the functional model). Finally, in the turning point models, structure was positively associated with SWL in both the landscape and functional models ( $\beta \mathrm{s}=.22$ and .20$)$, but no other associations were observed. It is worth noting that there were quite a few associations that were approaching statistical significance ( $p$ values between $.05-.10)$, which corresponded to $\beta$ s of .06-.10. We are not interpreting these individual 
associations, but collectively they suggest the possibility that there are many small associations, especially with personality traits, that require high statistical power to reliably detect ${ }^{3}$.

\section{Discussion}

In a large multi-lab effort, across three relatively large samples, we replicated a basic three-factor structure that captures current prominent features of life narratives employed in research within the field of personality psychology, findings that have meaningful theoretical, methodological, and practical contributions. We termed these factors Motivational and Affective Themes, Autobiographical Reasoning, and Structure. We identified two different models: the landscape model that contributes to our theoretical understanding of the structure of these features of life narratives, and the functional model that identifies a reduced set of narrative indicators that similarly captures the three factors identified. Although there was basic replication across many of the narrative prompts, our findings also suggest that the structure of life narratives may show some variation by prompt, particularly high point narratives. We also found that considering both the landscape and functional models is important for understanding the nuance in the structure of life narratives. Finally, we found associations with well-being primarily focused on motivational and affective themes, and associations with personality traits depended more specifically on prompts. We review the theoretical, methodological, and practical contributions of these results below.

\footnotetext{
${ }^{3}$ The analyses reported here included the narrative identity factors, traits, and satisfaction with life all in the same model, so are providing independent associations of each. However, some readers may be interested in the path estimates when narrative identity and traits are predicting satisfaction with life (which is simply a re-specification of the model presented in text), given interest in the field in the question of whether narrative identity factors have incremental associations with SWL over and above traits. In the high points models (landscape and functional) and turning point models (landscape and functional) the narrative structure factor was significantly associated with SWL, as were conscientiousness, extraversion, and neuroticism. In contrast, in the low point models (landscape and functional), conscientiousness, extraversion, and neuroticism were significant but structure was not. Thus, in these data only structure demonstrated some incremental validity over traits, which is consistent with the models that are presented in the main text. Full results are in supplemental tables S1 and S2.
} 


\section{Theoretical Contributions}

We focus here primarily on the theoretical contributions that this work makes to our understanding of individual differences in narrative identity, but we also discuss the contributions to our understanding of the structure of personality, at least in terms of dispositional traits and well-being.

Autobiographical Reasoning is about Change. The features that fall under this dimension (in both functional and landscape models) mostly hinge on some kind of narrated change in the narrator, primarily a self-reported change in one's understanding or interpretation of self or past events. Further, in the landscape model we see that this change is coupled with an experience of perceived growth, suggesting that the kind of change that is captured here is typically accelerative and positive, something that is seen in the theoretical underpinnings of the field of narrative identity (e.g., Habermas \& Bluck, 2000), and the coding systems. Interestingly, some prompts pull for change (e.g., turning points), but this factor structure held across other prompts suggesting that this is a broader theme in the ways in which people narrate themselves, at least within an American cultural context. Indeed, McAdams (e.g., 2015) has discussed the role of narrative within personality as a level that best captures personality dynamics, and inevitable change - as new events occur that require reflection and integration, and as people develop across time. Thus, autobiographical reasoning can be viewed as capturing a dynamic aspect of perceived change and development. And, at least in these American samples, this change is generally growth-oriented. We note, however, that capturing whether autobiographical reasoning is explicitly positive or negative may be important for certain research questions, particularly those related to well-being, which we discuss below. 
Affect and Motives are Tightly Linked in Life Narratives. There has been some uncertainty about how motivational aspects of narrative identity fit into a larger structure, as we discussed in the introduction. These data clearly show that motives and affect are linked. This could be due to the phenomenon that experiencing agency and communion are valued, positive components of human functioning, as is represented in various theoretical approaches (e.g., Deci \& Ryan, 1991; McAdams, 1985; Wiggins, 1991). This could also be because affect is inexorably built into the coding of agency and communion. Yet, in short, the experience of autonomy and of satisfying connections with others are positive states as revealed in the stories people tell about their lives.

Redemption is a Hybrid Construct. Redemption is one of the most studied constructs within the field of narrative identity (McAdams, 2006b). It has been found to be a critical construct in understanding well-being (e.g., McAdams et al., 2001), developmental tasks such as identity (e.g., McLean \& Pratt, 2006) and generativity (e.g., McAdams et al., 2001; McAdams \& Guo, 2015), health (Adler et al., 2015; Dunlop \& Tracy, 2013) and cultural contexts of identity development (Breen \& McLean, 2016; McLean \& Syed, 2015). Thus, we think it is important to reflect upon why it falls out of the functional model. We have long wondered whether redemption is about affect or autobiographical reasoning because it requires some of both. Such a large change in emotion to really redeem a negative event requires some reasoning, otherwise the story makes little sense. So, indeed, we see that it loaded on both autobiographical reasoning and motivational and affective themes in the landscape model. And it thus fell out of the functional model because of the nature of this cross-loading. And this cross-loading - truly sharing components of autobiographical reasoning and motivational and affective themes - may be one of the reasons it has been such a generative construct, offering explanation for such varied 
components of human functioning. It should be noted that growth, which has also been characterized as requiring the combination of autobiographical reasoning and a positive conclusion (Pals, 2006), demonstrated the same cross-loading pattern as redemption and may be similar in its robust associations with positive outcomes (Bauer et al, 2005; Pals, 2006; Lilgendahl \& McAdams, 2011).

Some Concepts are Defined by their Overlap. Though we were motivated to provide both a parsimonious and more complex model of the commonly assessed features of life narratives, we want to caution full embracement of the functional model for practical concerns. These last two contributions (the linking of motivational and affective themes and the hybridity of redemption) suggest that some features of narrative are inherently overlapping, and uncovering the commonalities appears to be theoretically and practically useful. Importantly, because redemption falls out of the functional model, we do not suggest that it does not have practical use in understanding well-being. In fact, some studies have shown that redemption has more weight in predicting well-being over basic affective tone (e.g., McAdams et al., 2001), suggesting that carrying the weight of two factors may offer meaningful explanatory power. Further, distinguishing affect and motives may not be justified within the narrative level of personality. In short, the narrative level of personality, at least as viewed in the landscape model, is a complex and interdependent entity.

Well-being is Most Closely Linked to Affect and Motives. Although we were slightly compromised in our ability to examine the same measures of well-being across samples, we do see that the motivational and affective themes factor was most reliably linked to the aspects of well-being that we assessed. This make sense, in thinking about the sense of purpose that motives provide, and the robust findings concerning the role of emotion in well-being (e.g., 
Diener, Suh, Lucas, \& Smith, 1999; McAdams et al., 2001). It is also interesting that autobiographical reasoning was not reliably linked to well-being. Many have argued that autobiographical reasoning is critical for processes of self-integration and identity development (e.g., McLean et al., 2007), but this may or may not relate to feeling good about the self. That is, one may understand the self and one's past, but that understanding is not necessarily about wellbeing unless it is linked to some positive interpretation (see King, 2001; Pals, 2006). Consistent with this idea, in the few instances when the distinction between positive and negative autobiographical reasoning has been made in coding systems, the associations with well-being are clear and in the expected directions (e.g., Graci et al., 2018; Lilgendahl \& McAdams, 2011).

Levels of Personality are Distinct, and Prompt May Matter. It is well-established narrative and traits are distinct levels of personality, with narrative showing consistent, but small associations with traits, as well as incremental validity in predicting well-being beyond traits (Adler et al., 2016; see also footnote 3). In the current study, we only had measures of personality traits in two of the three samples but, consistent with prior work, we saw relatively small associations with traits. These data also suggest that prompt may matter, something relatively uninvestigated in prior literature in which narratives are aggregated within persons (e.g., Blagov \& Singer, 2004; but see Mansfield et al., 2010) or only one prompt was used in a given study (e.g., Dunlop \& Tracy, 2013; McLean \& Pratt, 2006; Syed \& Azmitia, 2008). More fruitful investigations of the connections between levels of personality may need to consider the context of the narrated experience, at least context as differentiated by prompt. However, overall, we found that the more adaptive end of traits (for agreeableness, conscientiousness, and extraversion) was associated with motivational and affective themes in the high points, and with autobiographical reasoning for low points (for openness and agreeableness). This suggests that it 
may be that high openness is important for reasoning about low points, but not high points, given aspects of openness that center on some degree of uncertainty. We see the issue of prompts as being important in the relation between life narratives and traits as a fruitful avenue for future research, particularly in thinking about the role of intra-individual variability in both traits (Fleeson, 2001) and narrative (Dunlop, 2018; McLean et al., 2016), as well as the contexualization of various levels of personality (e.g., Mõttus, Kandler, Belidorn, Riemann, \& McCrae, 2017).

\section{Methodological Contributions: Despite Overall Invariance, Prompts Matter}

Generally, we found invariance across prompts for the three-factor structure, though there were some important deviations. We saw that high points were less consistent in holding the factor structure, and to see better model fit we needed to drop contamination (which is almost exclusively absent in high points), and sometimes agency. We take these results as an important reminder for researchers to consider the narrative material, including the prompt, in thinking about how to approach and code the data (Adler et al., 2017). Further, in thinking about relations to other constructs (e.g., well-being), prompts that allow for more variability in response (e.g., self-defining memories; see McLean et al., 2016) may be more effective.

Indeed, these findings about the importance of prompt are important to attend to because, as discussed above, study designs within the narrative field have often only employed one prompt or have aggregated prompts within person. Examination of the role of distinct prompts in narrative identity is newer to the field (Adler et al., 2015; Dunlop, Walker, \& Wiens, 2014; Lilgendahl \& McLean, 2018; McLean et al., 2016), and recent work suggests that prompts may matter. For example, Lilgendahl and McLean (2018) have found that narrative patterns in high points (compared to low points) are particularly important to understanding changes in life 
satisfaction over time, and even more specifically, high points about romance (compared to academics), in college samples where romance is a prime and relatively novel developmental task. Dunlop et al. (2014) similarly found that agency was more common in narratives about professional life, and communion more relevant to narratives about relationships in community samples. And, in examining the associations between narrative identity and well-being in a longitudinal sample, Adler and colleagues (2015) found that individual differences in agency, redemption, and contamination in low point and health challenge scenes, but not in high point scenes, were associated with different trajectories of well-being over the subsequent four years. Thus, researchers should consider the prompts of collected narratives in thinking about how best to capture the patterns of narration relevant to the topic of study, and what the associations between narrative features and other variables might mean (see also Galliher, McLean, \& Syed, 2017 for a similar discussion of narrative content).

\section{Practical Contributions}

At the outset, we want to emphasize that we are not intending to be prescriptive, but to offer these suggestions for consideration in study design. Indeed, given the time and effort involved in narrative coding, these findings offer some guidance to researchers wanting direction on the coding systems that best, or most cleanly, capture the three latent factors in the model. This is one of the major strengths of the functional model, as it identifies a reduced set of coding categories that adequately captures the three dimensions. For motivational and affective themes, the best candidates are affective tone, contamination, agency, and communion. These seem to be the features that best capture this dimension most closely linked to well-being. Again, the particularities of one study may guide which feature(s) to use. For example, those interested in relational aspects of positive functioning may find communion most useful. 
Exploratory processing (Pals, 2006), meaning-making (McLean \& Pratt, 2006), and change connections (Pasupathi, Mansour, \& Brubaker, 2007) are the clearest candidates for capturing autobiographical reasoning. Importantly, each of these systems is distinct in ways that might matter for a given study. Exploratory processing captures the activity of reflection, and meaning-making and change connections capture the presumed culmination of that processing an actual lesson or insight. Meaning-making captures only insights that are new, or about change, and self-event connections capture insights about change and stability. Thus, these nuances might guide decision making in which system to choose if researchers are interested in representing autobiographical reasoning as a latent variable.

Finally, for structure, the clearest candidates for capturing this are facts and contextual and chronological coherence. These are the components that capture less interpretive components of narrative - observable details of an event, as well as time and location.

These findings from the functional model, coupled with the discussion of prompts above, provide some guidance for researchers wishing to conduct further studies within the field. For example, capturing affective tone in high points may be particularly key for well-being. But, again, we caution readers to not embrace the functional model without attention to the landscape model, which reveals the inter-relations of constructs, and those constructs that might carry more "narrative weight" in their cross-loadings in predicting functioning, such as redemption and growth. Ultimately, which model to pursue in future work should be dictated by the particular research question and particularities of the study context. The models identified in the present study should be considered in terms of whether there is primary interest in the specific narrative constructs, the underlying latent variables, or both.

\section{Limitations and Future Directions}


Below we detail five areas that were relatively unexamined in the present study, that are limitations of the present work and opportunities for future studies. That is, the replication and reliability of these factors are impressive, but there is always more work to be done. We focus on several domains of interest, and do not intend these to be the only relevant domains; indeed, given the generativity of narrative data, there are many more domains to which these data could apply.

Beyond Healthy, American Samples. Although we have presented data across three samples, which include college-going participants from three quite different institutions, and one diverse adult community sample, these are generally healthy and normative samples. For example, the emphasis on autobiographical reasoning as growth oriented and positive may reflect the general high functioning of our samples. Therefore, application of this structure to more clinical samples may be limited. We have also reported data from participants captured in American context. We have no reason to expect that these factors would replicate crossculturally, or that the narrative features that make up the factors are cross-culturally appropriate. For example, McAdams (2006b) has argued that redemption is a dominant American phenomenon, and recent evidence supports this at least as it relates to well-being (Eriksson, McLean \& Frisén, 2018).

Beyond Well-being. We began this project guided by the robust work that has been done in the field on well-being. However, there are other components of human functioning in which narration plays a role. Perhaps most prominently is the study of identity development. The autobiographical reasoning factor is probably the factor most closely associated with identity development - as making sense of how past events connect to and reflect the self is an identity process (McLean et al., 2007). Prior work has examined autobiographical reasoning in relation 
to many aspects of identity, including ethnic identity (e.g., Syed \& Azmitia, 2010), gender identity (e.g., Fivush \& Marin, 2018; McLean, Shucard, \& Syed, 2017), identity statuses (e.g., McLean \& Pratt, 2006; Syed \& Azmitia, 2008), disability identity (Adler, 2018), and college major choice (Syed, 2010), to name a few. Other work has examined patterns in narration in relation to moral development (e.g., Pasupathi \& Wainryb, 2010), political orientation (McAdams, Albaugh, Farber, Daniels, Logan, \& Olson, 2008), and health behaviors (Dunlop \& Tracy, 2013), among other topics. There is also a robust area of study examining the development of narrative skills where structure and autobiographical reasoning are prime factors (e.g., Habermas \& de Silveira, 2008; Reese, Jack, \& White, 2010). Thus, we encourage researchers to consider applying these structural models, or this structural approach, to other areas of study beyond well-being.

Beyond Change. Despite the reliable and robust factor of autobiographical reasoning focused on change, seeing the self as maintaining some stability through time is also important for identity and well-being (Pasupathi et al., 2007). However, the field has been biased towards conceptualizing (and coding) narratives for markers of change, as reflected in only one coding system that captures stability (Pasupathi et al., 2007). That is, by far, most of the narrative features in studies focused on well-being capture issues of change from the emotional valence (e.g., redeeming a negative event) to meaning (viewing the self as changed or transformed following the experience of challenge). However, narrative is not only about change. We can also narrate events in ways that serve to explain or maintain a sense of stability in self, which may also be important to psychological functioning (McLean, 2008; Pasupathi et al., 2007). Capturing stability in various ways, such as stagnation or healthy consistency, may open up new ways of understanding narrative identity and well-being (Dunlop, 2018; Fivush, Habermas, \& 
Reese, 2018; McLean Köber, \& Haraldsson, 2018; Pasupathi \& Wainryb, 2018; Singer, 2018).

Finally, in relation to both autobiographical reasoning and stability, researchers may also want to think about capturing the phenomenon of not making connections in narrative. That is, there may be something meaningful about not linking events to the self (see Mansfield et al., 2010), even when asked to do so.

Beyond Big Stories. The narratives collected in these studies are what we call 'big stories' (see Thorne, 2004) - stories central to the self and to defining narrative identity, and that are used prominently in the field of personality psychology. These are the stories shared that offer entre into and intimacy with the person (McAdams, 1993). However, substantial work has shown that these are not necessarily the kinds of stories shared regularly in day-to-day interaction with friends, colleagues, and family (Bamberg, 2004; Bohanek, Marin, Fivush, \& Duke, 2006; Pasupathi \& Hoyt, 2009). We also know that more commonly shared stories about what happened over the course of the day, 'small stories,' are different from these big stories, perhaps most centrally in processes of autobiographical reasoning. Individuals do not often engage in effortful reflection and meaning-making about trips to the grocery store. Part of the differences in these kinds of stories is due to methods, as small stories are often collected in conversational contexts, which pull for different kinds of stories. For example, in telling a story to an intimate (versus a researcher), one may need to engage in less contextual coherence as a shared understanding is already established. Thus, the landscape of small stories may look quite different than that of big stories, with different narrative features coming to the fore.

Beyond Quantification. We close by reminding the reader that the endeavor of the present study takes as a given the merits of quantifying personal narratives for the study of narrative identity. However, there is a thriving segment of the field of scholarship on narrative 
dedicated to illuminating and explicating the nuance of personal stories (see Adler, 2018; Hammack, 2011; Josselson, 2009). We do not regard these approaches as at all mutually exclusive. Narrative identity is a complex, dynamic, socially-situated phenomenon, and the results of our present analyses serve to organize its aspects that have most commonly been examined using quantitative tools. But the field continues to need exploratory, qualitative, generative work. Indeed, these other approaches may help to illuminate aspects of narrative that we have not adequately addressed (see Adler, 2018; Dunlop, 2018; Fivush et al., 2018; McAdams, 2018; McLean et al., 2018), including the way narratives promote identity stability, which was not well-captured in the present endeavor (Pasupathi \& Wainryb, 2018). Indeed, one of the strengths of the narrative identity literature is that it encompasses the use multiple levels of analysis to great effect.

In conclusion, people construct and tell stories about their lives, those stories matter for their functioning both currently and prospectively, and they are a distinct and meaningful level of personality. Our findings suggest that narratives can be captured by the dimensions of motivational and affective themes, autobiographical reasoning, and structure. This dimensional understanding provides a foundation to capitalize on in our future work. In fact, in establishing the organization for our existing approaches to quantifying narratives, we can begin to talk in a common language about what features of narratives are important for personality-relevant (and important) questions, such as the naturalistic processes by which these features of narratives develop, how to intervene and shape narratives that facilitate well-being, and how these dimensions develop across the lifespan. We offer the identification of the initial Big Three of narrative identity as a foundation for future work in this area - capturing extant approaches and 
opening up the new lines of research. We hope that this structural approach offers conceptual richness and organization, and is also generative for the next movements in the field.

\section{References}

Adler, J.M. (2012). Living into the story: Agency and coherence in a longitudinal study of narrative identity development and mental health over the course of psychotherapy. Journal of Personality and Social Psychology, 102(2), 367-389. doi: 10.1037/a0025289

Adler, J.M. (2018). Stability and change in narrative identity: Introduction to the special section on repeated narration. Manuscript under review.

Adler, J.M. (2018). Bringing the (disabled) body to personality psychology: A case study of Samantha. Journal of Personality. doi: 10.1111/jopy.12364

Adler, J.M., Chin, E.D., Kolisetty, A.P., \& Oltmanns, T.F. (2012). The distinguishing characteristics of narrative identity in adults with features of Borderline Personality Disorder: An empirical investigation. Journal of Personality Disorders, 26, 498-512. doi: $10.1521 /$ pedi.2012.26.4.498

Adler, J.M., Dunlop, W.L., Fivush, R., Lilgendahl, J.P., Lodi-Smith, J., McAdams, D.P., McLean, K.C., Pasupathi, M., \& Syed, M. (2017). Research methods for studying narrative identity: A primer. Social Psychological and Personality Science, 8(5), 519527. https://doi.org/10.1177/1948550617698202

Adler, J.M. \& Hershfield, H.E. (2012). Mixed emotional experience is associated with and precedes improvements in psychological well-being. PLoS ONE, 7(4), 1-10. https://doi.org/10.1371/journal.pone.0035633

Adler, J.M., Lodi-Smith, J., Philippe, F.L., Houle, I. (2016). The incremental validity of narrative 
identity in predicting well-being: A review of the field and recommendations for the future. Personality and Social Psychology Review, 20(2), 142-175. doi:

\section{$10.1177 / 1088868315585068$}

Adler, J.M., Skalina, L.M., \& McAdams, D.P. (2008). The narrative reconstruction of psychotherapy and psychological health. Psychotherapy Research, 18(6), 719-734. doi: $10.1080 / 10503300802326020$

Adler, J.M., Turner, A.F., Brookshier, K.M., Monahan, C., Walder-Biesanz, I., Harmeling, L.H., Albaugh, M., McAdams, D.P., Oltmans, T.F. (2015). Variation in narrative identity is associated with trajectories of mental health over several years. Journal of Personality and Social Psychology, 108(3), 476-496. doi: 10.1037/a0038601

Adler, J.M., Waters, T.E.A., Poh, J., \& Seitz, S. (2018). The nature of narrative coherence: An empirical approach. Journal of Research in Personality, 74, 30-34. DOI: 10.1016/j.jrp.2018.01.001

Baerger, D. R., \& McAdams, D. P. (1999). Life story coherence and its relation to psychological well-being. Narrative Inquiry, 9, 69-96. http://dx.doi.org/10.1075/ni.9.1.05bae

Bakan, D. (1966). The duality of human existence. Boston: Beacon Press.

Bamberg, M. (2004). "We are young, responsible, and male": Form and function of 'slutbashing' in the identity constructions in 15-year-old males. Human Development, 47, 331-353.

Banks, M.V., \& Salmon, K. (2013). Reasoning about the self in positive and negative ways: Relationship to psychological wellbeing in young adulthood. Memory, 21, 10-26. doi: $10.1080 / 09658211.2012 .707213$

Bauer, J. J., McAdams, D. P., Sakaeda, A. R. (2005). Interpreting the good life: Growth 
memories in the lives of mature, happy people. Journal of Personality and Social Psychology, 88, 203-217. DOI: 10.1037/0022-3514.88.1.203

Blagov, P. S., \& Singer, J. A. (2004). Four dimensions of self-defining memories (specificity, meaning, content, and affect) and their relationships to self-restraint, distress, and repressive defensiveness. Journal of Personality, 72, 481-511. DOI: 10.1111/j.00223506.2004.00270.x

Block, J. (1995). A contrarian view of the five-factor approach to personality description. Psychological Bulletin, 117, $187-215$.

Boals, A., \& Schuettler, D. (2010). A double-edged sword: Event centrality, PTSD, and posttraumatic growth. Applied Cognitive Psychology, 25 (5), 817-822. https://doi.org/10.1002/acp.1753

Bohanek, J. G., Marin, K. A., Fivush, R., \& Duke, M. P. (2006). Family narrative interaction and children's sense of self. Family Process, 45, 39-54.

Breen, A. V., \& McLean, K.C. (2016). The intersection of personal and master narratives: Is redemption for everyone (pp. 197 - 214)? In B. Schiff \& S. Patron (Eds.), Narrative Matters: Papers from the 2012 Conference. New York: Oxford University Press.

Bruner, J. S. (1990). Acts of meaning. Cambridge, MA: Harvard University Press.

Deci, E. L., \& Ryan, R. M. (1991). A motivation approach to self: Integration in personality. Nebraska Symposium on Motivation: Vol. 38. Perspectives on motivation (pp. 276 - 288). Lincoln, NE: University of Nebraska Press.

DeYoung, C. G. (2015). Cybernetic big five theory. Journal of Research in Personality, 56, 3358. http://dx.doi.org/10.1016/j.jrp.2014.07.004

Diener, E., Emmons, R. A., Larsen, R. J., \& Griffin, S. (1985). The Satisfaction with Life Scale. 
Journal of Personality Assessment, 49, 71-75.

https://doi.org/10.1207/s15327752jpa4901_13

Diener, E., Suh, E. M., Lucas, R. E., \& Smith, H. L. (1999). Subjective well-being: Three decades of progress. Psychological Bulletin, 125, 276-302. http://dx.doi.org/10.1037/0033-2909.125.2.276

Dunlop, W. L. (2018). From the Story to the Storyteller: Life Narrations from a Personological Perspective. Manuscript Under Review.

Dunlop, W. L., \& Tracy, J. L. (2013). Sobering stories: Narratives of self-redemption predict behavioral change and improved health among recovering alcoholics. Journal of Personality and Social Psychology, 104, 576-590. doi: 10.1037/a0031185

Dunlop, W. L., Walker, L. J., \& Wiens, T. K. (2014). The nature of professional and relational self-aspects at the goal and narrative levels of personality. British Journal of Social Psychology, 53, 595-604. doi:10.1111/bjso.12072

Empirisoft (2008). Media Lab v2008 [software]. <http://www.empirisoft.com/>.

Eriksson, P. L., McLean, K. C., \& Frisén, A. (2018). Narrating difficult experiences - A cultural framework for telling identity narratives in Sweden. Manuscript in Preparation.

Fivush, R. (2001). Owning experience: Developing subjective perspec- tive in autobiographical narratives. In C. Moore \& K. Lemmon (Eds.), The self in time: Developmental perspectives (pp. 35-52). Mahwah, NJ: Lawrence Erlbaum.

Fivush, R., \& Marin, K. (2018). Development of a gendered narrative identity. In C. B. Travis, J. W. White, A. Rutherford, W. S. Williams, S. L. Cook, \& K. F. Wyche (Eds.), APA handbooks in psychology series. APA handbook of the psychology of women: History, 
theory, and battlegrounds (pp. 473-487). Washington, DC, US: American Psychological Association. http://dx.doi.org/10.1037/0000059-024

Fivush, R., Habermas, H., \& Reese, E. (2018). Retelling lives: Narrative style and stability of highly emotional events over time. Manuscript Under Review.

Fleeson, W. (2001). Toward a structure- and process-integrated view of personality: Traits as density distributions of states. Journal of Personality and Social Psychology, 80(6), 1011-1027. http://dx.doi.org/10.1037/0022-3514.80.6.1011

Galliher, R., McLean, K. C., Syed, M. (2017). An Integrated Model for Studying Identity Content in Context. Developmental Psychology, 53, 2011-2022. doi: $10.1037 / \operatorname{dev} 0000299$

Graci, M. E., Watts, A.L., \& Fivush, R. (2018). Examining the factor structure of narrative 1232. doi: $10.1080 / 09658211.2018 .1441422$

Greenhoot, A. F., McLean, K. C., Wood, B., Yoder, A. (2013). The costs and benefits of reflection in personal narratives: The type of memory matters. Paper presented at the Society for Research in Child Development, Seattle. WA.

Greenhoot, A.F., Sun, S., \& Bunnell, S.L., \& Lindboe, K. (2013). Making sense of childhood trauma: Memory qualities and psychological symptoms in emerging adults with and without abuse histories. Memory, 21(1), 125 - 142. doi: 10.1080/09658211.2012.712975

Habermas, T., \& Bluck, S. (2000). Getting a life: The development of the life story in adolescence. Psychological Bulletin, 126, 748-769. http://dx.doi.org/10.1037/00332909.126.5.748

Habermas, T., \& de Silveira, C. (2008). The development of global coherence in life narratives 
across adolescence: Temporal, causal, and thematic aspects. Developmental Psychology, 44, 707-721. doi: 10.1037/0012-1649.44.3.707

Hammack, P. L. (2011). Narrative and the politics of identity: The cultural psychology of Israeli and Palestinian youth. New York, NY: Oxford University Press.

Hemphill, J. F. (2003). Interpreting the magnitudes of correlation coefficients. American Psychologist, 58(1), 78-79. http://dx.doi.org/10.1037/0003-066X.58.1.78

Hopwood, C. J., \& Donnellan, M. B. (2010). How should the internal structure of personality inventories be evaluated? Personality and Social Psychology Review, 14, 332-46. doi: $10.1177 / 1088868310361240$

John, O. P., Angleitner, A., \& Ostendorf, F. (1988). The lexical approach to personality: A historical review of trait taxonomic research. European Journal of Personality, 2(3), 171203. http://dx.doi.org/10.1002/per.2410020302

John, O. P., \& Srivastava, S. (1999). The Big Five Trait taxonomy: History, measurement, and theoretical perspectives. In L. A. Pervin \& O. P. John (Eds.), Handbook of personality: Theory and research (2nd ed., pp. 102-138). New York, NY: Guilford Press.

Josselson, R. (2009). The present of the past: Dialogues with memory over time. Journal of Personality, 77(3), 647-668. http://dx.doi.org/10.1111/j.1467-6494.2009.00560.x

Kauermann, G., \& Carroll, R. J. (2001). A note on the efficiency of sandwich covariance matrix estimation. Journal of the American Statistical Association, 96, 1387-1396. https://doi.org/10.1198/016214501753382309

Kim, E. S., Dedrick, R. F., Cao, C., \& Ferron, J. M. (2016). Multilevel factor analysis: Reporting guidelines and a review of reporting practices. Multivariate Behavioral Research, 51(6), 881-898. https://doi.org/10.1080/00273171.2016.1228042 
King, L. A. (2001). The hard road to the good life: The happy, mature person. Journal of Humanistic Psychology, 41, 5172.

Lilgendahl, J. P., \& McAdams, D. P. (2011). Constructing stories of self-growth: How individual differences in patterns of autobiographical reasoning relate to well- being in midlife. Journal of Personality, 79, 391-428. doi: 10.1111/j.1467-6494.2010.00688.x.

Lilgendahl, J. P., \& McLean, K. C. (2018). Narrative Identity Processes and Changes in Wellbeing Across the Transition to College: A Contextualized Approach. Manuscript in Preparation.

Lodi-Smith, J., Geise, A. C., Roberts, B. W., \& Robins, R. W. (2009). Narrating personality change. Journal of Personality and Social Psychology, 96, 679-689. doi: $10.1037 / \mathrm{a} 0014611$

Lysaker, P. H., Clements, C. A., Plascak-Hallberg, C. D., Knipscheer, S. J., \& Wright, D. E. (2002). Insight and personal narratives of illness in schizophrenia. Psychiatry: Interpersonal and Biological Processes, 65(3), 197-206. http://dx.doi.org/10.2975/29.2005.66.68

Manczak, E. M., Zapata-Gietl, C., \& McAdams, D. P. (2014). Regulatory focus in the life story: Prevention and promotion as expressed in three layers of personality. Journal of Personality and Social Psychology, 106, 169-181. doi: 10.1037/a0034951.

Mansfield, C., McLean, K. C., \& Lilgendahl, J. P. (2010). Narrating Traumas and Transgressions: Links between Narrative Processing, Wisdom, and Well-being. Narrative Inquiry, 20, 246 - 273. http://dx.doi.org/10.1075/ni.20.2.02man

McAdams, D. P. (1985). Power, intimacy, and the life story. New York: Guilford. 
McAdams, D. P. (1993). The stories we live by: Personal myths and the making of the self. New York: William Morrow.

McAdams, D. P. (1995). What do we know when we know a person? Journal of Personality, 63, 365-396. https://doi.org/10.1111/j.1467-6494.1995.tb00500.x

McAdams, D. P. (2001). The psychology of life stories. Review of General Psychology, 5, 100122. http://dx.doi.org/10.1037/1089-2680.5.2.100

McAdams, D. P. (2006a). Foley Center, Guided Autobiography<http://www.sesp. northwestern.edu/foley/instruments/guided>. Retrieved November 20, 2006.

McAdams, D. P. (2006). The redemptive self: Stories Americans live by. New York: Oxford University Press. http://www.sesp.northwestern.edu/docs/LifeStoryInterview .pdf

McAdams, D. P. (2008). The Life Story Interview. Retrieved from

McAdams, D. P. (2015). The art and science of personality development. New York: Guilford Press.

McAdams, D. P. (2018). Commentary: Continuity and growth in the life story - or is it stagnation and flux? Manuscript under review.

McAdams, D. P., Albaugh, M., Farber, E., Daniels, J., Logan, R. L., Olson, B. Family metaphors and moral intuitions: how conservatives and liberals narrate their lives. Journal of Personality and Social Psychology, 95, 978 - 990. doi: 10.1037/a0012650.

McAdams, D. P., Anyidoho, N. A., Brown, C., Huang, Y. T., Kaplan, B., \& Machado, M. A. (2004). Traits and stories: Links between dispositional and narrative features of personality. Journal of Personality, 72, 761-784.

McAdams, D. P., Bauer, J. J., Sakaeda, A. R., Anyidoho, N. A., Machado, M. A., Magrino- 
Failla, K., White, K. W., \& Pals, J. L. (2006). Continuity and change in the life story: A longitudinal study of autobiographical memories in emerging adulthood. Journal of Personality, 74, 1371-1400. DOI:10.1111/j.1467-6494.2006.00412.x

McAdams, D. P., \& Guo, J. (2015). Narrating a generative life. Psychological Science, 26, 475483. https://doi.org/10.1177/0956797614568318

McAdams, D. P., \& McLean, K. C. (2013). Narrative identity. Current Directions in Psychological Science, 22, 233-238. https://doi.org/10.1177/0963721413475622

McAdams, D. P., \& Pals, J. L. (2006). A new Big Five: Fundamental principles for an integrative science of personality. American Psychologist, 61, 204-217. DOI: 10.1037/0003066X.61.3.204

McAdams, D. P., Reynolds, J., Lewis, M., Patten, A., \& Bowman, P. J. (2001). When bad things turn good and good things turn bad: Sequences of redemption and contamination in life narrative, and their relation to psychosocial adaptation in midlife adults and in students. Personality and Social Psychology Bulletin, 27, 472-483. http://dx.doi.org/10.1177/0146167201274008

McCrae, R. R., \& Costa, P. T., Jr. (2004). A contemplated revision of the NEO Five-Factor Inventory. Personality and Individual Differences, 36, 587-596.

McCrae, R. R., \& Costa, P. T., Jr. (2008). The five-factor theory of personality. In O. P. John, R. W. Robins, \& L. A. Pervin (Eds.), Handbook of personality: Theory and research (pp. 159-181). New York, NY, US: Guilford Press.

McLean, K. C. (2008). Stories of the young and the old: Reflections on self-continuity. Developmental Psychology, 44, 254-164.

McLean, K. C., Breen, A., \& Fournier, M. A. (2010). Adolescent identity development: 
Narrative meaning-making and memory telling. Journal of Research on Adolescence, 20, 166 - 187. doi: $10.1080 / 09658211.2012 .706614$

McLean, K. C., Köber, C., \& Haraldsson, K. (2018). The repeated narration of specific events and identity stability in mid-life. Manuscript Under Review.

McLean, K. C., \& Pals, J. L. (2008). Reminiscence functions: Emotional valence, age and wellbeing. Memory, 751-672. DOI: 10.1080/741938202

McLean, K. C., Pasupathi, M., Fivush, R., Greenhoot, A. F., \& Wainryb, C. (2016). Does within person variability in narration matter and for what? Journal of Research in Personality, 69, 55 - 66. DOI: 10.1016/j.jrp.2016.04.003

McLean, K. C., Pasupathi, M., \& Pals. J. L. (2007). Selves creating stories creating selves: A process model of narrative self development in adolescence and adulthood. Personality and Social Psychology Review, 11, 262-278. https://doi.org/10.1177/1088868307301034

McLean, K. C., \& Pratt, M. W. (2006). Life's little (and big) lessons: Identity statuses and meaning-making in the turning point narratives of emerging adults, Developmental Psychology, 42, 714-722. DOI: 10.1037/0012-1649.42.4.714

McLean, K. C., Shucard, H., \& Syed, M. (2017). Applying the Master Narrative Framework to Gender Identity in Emerging Adulthood: Emerging Adulthood, 5, 93-105. https://doi.org/10.1177/2167696816656254

McLean, K. C. \& Syed, M. (2015). Personal, Master, and Alternative Narratives: An Integrative Framework for Understanding Identity Development in Context. Human Development, 58, 318 - 349. DOI:10.1159/000445817

McLean, K. C., \& Thorne, A. (2003). Late adolescents' self-defining memories about 
relationships. Developmental Psychology, 39, 635-645. http://dx.doi.org/10.1037/00121649.39.4.635

Muthén, L. K., \& Muthén, B. O. (2010). Mplus user's guide (6th ed.). Los Angeles, CA: Author.

Mõttus, R., Kandler, C., Belidorn, W., Riemann, R., \& McCrae, R. R. (2017). Personality traits below facets: The consensual validity, longitudinal stability, heritability, and utility of pesonality nuances. Journal of Personality and Social Psychology, 112, 474 - 490. doi: $10.1037 / \operatorname{pspp} 0000100$

Mundfrom, D. J., Shaw, D. G., \& Ke, T. L. (2005). Minimum sample size recommendations for conducting factor analyses. International Journal of Testing, 5(2), 159-168.

O'connor, B. P. (2000). SPSS and SAS programs for determining the number of components using parallel analysis and Velicer's MAP test. Behavior research methods, instruments, \& computers, 32(3), 396-402. https://doi.org/10.3758/BF03200807

Pals, J. L. (2006). Narrative Identity Processing of Difficult Life Experiences: Pathways of Personality Development and Positive Self-Transformation in Adulthood. Journal of Personality, 64, 1079 - 1110. https://doi.org/10.1111/j.1467-6494.2006.00403.x

Pasupathi, M. (2001). The social construction of the personal past and its implications for adult development. Psychological Bulletin, 127(5), 651-672.

Pasupathi, M., \& Hoyt, T. (2009). The development of narrative identity in late adolescence and emergent adulthood: The continued importance of listeners. Developmental Psychology, 45(2), 558-574. http://dx.doi.org/10.1037/a0014431

Pasupathi. M., \& Wainryb, C. (2010). On telling the whole story: Facts and interpretations in autobiographical memory narratives from childhood through mid-adolescence. Developmental Psychology, 46, 735-746. 
Pasupathi, M., \& Wainryb, C. (2018). Ghosts in the Story: The Role of Audiences in Stability and Change in Twice-told Life. Manuscript Under Review.

Pasupathi, M., Mansour, E., \& Brubaker, J. R. (2007). Developing a life story: Constructing relations between self and experience in autobiographical narratives. Human Development, 50, 85-110. doi:10.1159/000100939

Pennebaker, J. W. (1982). The psychology of physical symptoms. New York, NY, US: SpringerVerlag Publishing. http://dx.doi.org/10.1007/978-1-4613-8196-9

Philippe, F. L., Koestner, R., Lecours, S., Beaulieu-Pelletier, G., \& Bois, K. (2011). The role of autobiographical memory networks in the experience of negative emotions: How our remembered past elicits our current feelings. Emotion, 11(6), 12791290. http://dx.doi.org/10.1037/a0025848

Radloff, L. S. (1977). The CES-D scale a self-report depression scale for research in the general population. Applied Psychological Measurement, 1(3), 385-401. https://doi.org/10.1177/014662167700100306

Reese, E., Haden, C. A., Baker-Ward, L., Bauer, P., Fivush, R., \& Ornstein, P. A. (2011). Coherence of personal narratives across the lifespan: A multidimensional model and coding method. Journal of Cognition and Development, 12(4), 424-462. DOI: $10.1080 / 15248372.2011 .587854$

Reese, E., Jack, F., \& White, N. (2010). Origins of adolescents' autobiographical memories. Cognitive Development, 25, 352-367. doi:10.1016/j.cogdev.2010.08.006

Sarbin, T. (1986). The narrative as a root metaphor for psychology. In T. Sarbin (Ed.), Narrative psychology: The storied nature of human conduct (pp. 3-21). New York: Praeger. 
Singer, J. A. (2004). Narrative identity and meaning making across the adult lifespan: An introduction. Journal of Personality, 72, 437-459. DOI: 10.1111/j.00223506.2004.00268.x

Singer, J. A., (2018). Repetition is the Scent of the Hunt: A Clinician's Application of Narrative Identity to a Longitudinal Life Study. Manuscript Under Review.

Singer, J., Rexhaj, B., \& Baddeley, J. (2007). Older, wiser, and happier? Comparing older adults' and college students' self-defining memories. Memory, 15(8), 886-898. DOI: $10.1080 / 09658210701754351$

Singer, J. A., \& Moffitt, K. H. (1991-1992). An experimental investigation of specificity and generality in memory narratives. Imagination, Cognition \& Personality, 11, 233-257. http://dx.doi.org/10.2190/72A3-8UPY-GDB9-GX9K

Syed, M. (2010). Developing an integrated self: Academic and ethnic identities among ethnically diverse college students. Developmental Psychology, 46, 1590-1604. http://dx.doi.org/10.1037/ a0020738

Syed, M., \& Azmitia, M. (2008). A narrative approach to ethnic identity in emerging adulthood: Bringing life to the identity status model. Developmental Psychology, 44, 1012-1027. http://dx.doi. org/10.1037/0012-1649.44.4.1012

Syed, M., \& Azmitia, M. (2010). Narrative and ethnic identity exploration: A longitudinal account of emerging adults' ethnicity-related experiences. Developmental Psychology, 46, 208-219. doi:10.1037/a0017825

Syed, M., \& Nelson, S. C. (2015). Guidelines for establishing reliability when coding narrative data. Emerging Adulthood, 3, 375- 387. https://doi.org/10.1177/2167696815587648

Thorne, A. (2004). Putting the person into social identity. Human Development, 253, 1-5. 
https://doi.org/10.1159/00008138

Waters, E. A., \& Fivush, R. (2015). Relations Between Narrative Coherence, Identity, and Psychological Well-being in Emerging Adulthood. Journal of Personality, 83, 441 - 451. doi: $10.1111 /$ jopy. 12120

Watson, D., Clark, L.A., \& Tellegen, A. (1988). Development and validation of brief measures of positive and negative affect: The PANAS scales. Journal of Personality and Social Psychology, 54, 1063-1070. http://dx.doi.org/10.1037/0022-3514.54.6.1063

Wiggins, J. S. (1991). Agency and communion as conceptual coordinates for the understanding and measurement of interpersonal behavior. In W. M. Grove \& D. Ciccetti (Eds.), Thinking clearly about psychology: Vol. 2. Personality and psychopathology (pp. 89-113). Minneapolis, MN: University of Minnesota Press. 
Table 1

Descriptive Statistics and Bivariate Correlations for Sample 1, Memory 1

\begin{tabular}{|c|c|c|c|c|c|c|c|c|c|c|c|c|c|c|c|c|c|}
\hline & $M$ & $S D$ & 1 & 2 & 3 & 4 & 5 & 6 & 7 & 8 & 9 & 10 & 11 & 12 & 13 & 14 & 15 \\
\hline 1 Growth & 1.32 & 0.75 & -- & & & & & & & & & & & & & & \\
\hline 2 Exploratory Processing & 1.76 & 0.86 & .55 & -- & & & & & & & & & & & & & \\
\hline 3 Meaning-making & 0.78 & 1.19 & .49 & .55 & -- & & & & & & & & & & & & \\
\hline 4 Stability Connections & 0.53 & 0.56 & -.16 & -.07 & -.12 & -- & & & & & & & & & & & \\
\hline 5 Change Connections & 0.65 & 0.61 & .43 & .46 & .46 & -.27 & -- & & & & & & & & & & \\
\hline 6 Facts & 2.01 & 0.82 & -.09 & -.21 & -.05 & .05 & -.08 & -- & & & & & & & & & \\
\hline 7 Interpretations & 1.82 & 0.76 & .12 & .40 & .19 & .09 & .25 & .14 & -- & & & & & & & & \\
\hline 8 Contextual Coherence & 2.62 & 0.53 & -.01 & -.06 & -.06 & -.01 & .03 & .25 & .12 & -- & & & & & & & \\
\hline 9 Chronologic Coherence & 2.82 & 0.46 & -.05 & -.05 & .00 & .07 & -.02 & .16 & .13 & .23 & -- & & & & & & \\
\hline 10 Thematic Coherence & 2.23 & 0.72 & .32 & .44 & .40 & .00 & .41 & .16 & .41 & .08 & .06 & -- & & & & & \\
\hline 11 Affective Tone & 2.33 & 0.69 & .36 & .10 & .12 & -.05 & .08 & -.11 & -.13 & -.12 & -.07 & .06 & -- & & & & \\
\hline 12 Ending Valence & 1.94 & 1.27 & .60 & .38 & .32 & -.03 & .27 & -.09 & .08 & -.03 & -.01 & .26 & .65 & -- & & & \\
\hline 13 Redemptive & 0.21 & 0.40 & .53 & .32 & .28 & -.05 & .23 & -.01 & .05 & -.01 & -.01 & .27 & .31 & .57 & -- & & \\
\hline 14 Contamination & 0.29 & 0.45 & -.23 & -.12 & -.03 & .06 & -.03 & .12 & .09 & .04 & .14 & -.01 & -.19 & -.25 & -.33 & -- & \\
\hline 15 Agency & 0.99 & 1.16 & .46 & .27 & .24 & -.02 & .17 & -.03 & .03 & -.09 & -.03 & .18 & .59 & .64 & .39 & -.20 & -- \\
\hline 16 Communion & 1.43 & 1.15 & .25 & .06 & .05 & -.08 & .08 & .06 & -.11 & .02 & -.04 & .08 & .49 & .46 & .27 & -.18 & .43 \\
\hline
\end{tabular}


The Structure of Narrative Identity 67

Table 2

Descriptive Statistics and Bivariate Correlations for Sample 1, Memory 2

\begin{tabular}{|c|c|c|c|c|c|c|c|c|c|c|c|c|c|c|c|c|c|}
\hline & $M$ & $S D$ & 1 & 2 & 3 & 4 & 5 & 6 & 7 & 8 & 9 & 10 & 11 & 12 & 13 & 14 & 15 \\
\hline 1 Growth & 1.33 & 0.77 & -- & & & & & & & & & & & & & & \\
\hline 2 Exploratory Processing & 1.69 & 0.84 & .63 & -- & & & & & & & & & & & & & \\
\hline 3 Meaning-making & 0.65 & 1.13 & .58 & .58 & -- & & & & & & & & & & & & \\
\hline 4 Stability Connections & 0.57 & 0.60 & -.20 & -.10 & -.16 & -- & & & & & & & & & & & \\
\hline 5 Change Connections & 0.59 & 0.62 & .45 & .51 & .48 & -.28 & -- & & & & & & & & & & \\
\hline 6 Facts & 2.01 & 0.80 & -.17 & -.26 & -.19 & .09 & -.17 & -- & & & & & & & & & \\
\hline 7 Interpretations & 1.88 & 0.72 & .15 & .32 & .17 & .15 & .21 & .21 & -- & & & & & & & & \\
\hline 8 Contextual Coherence & 2.50 & 0.59 & -.04 & -.04 & -.08 & .03 & -.03 & .36 & .16 & -- & & & & & & & \\
\hline 9 Chronologic Coherence & 2.76 & 0.53 & -.04 & -.09 & -.08 & .04 & -.01 & .33 & .16 & .27 & -- & & & & & & \\
\hline 10 Thematic Coherence & 2.25 & 0.70 & .33 & .42 & .39 & .03 & .36 & .11 & .46 & .06 & -.04 & -- & & & & & \\
\hline 11 Affective Tone & 2.41 & 0.77 & .35 & .16 & .13 & -.11 & .12 & -.12 & -.17 & -.04 & -.06 & -.01 & -- & & & & \\
\hline 12 Ending Valence & 2.08 & 1.38 & .58 & .40 & .31 & -.16 & .29 & -.10 & .01 & .00 & -.06 & .19 & .68 & -- & & & \\
\hline 13 Redemptive & 0.22 & 0.42 & .45 & .35 & .30 & -.14 & .24 & -.04 & .07 & -.01 & -.10 & .26 & .32 & .53 & -- & & \\
\hline 14 Contamination & 0.32 & 0.47 & -.23 & -.19 & -.15 & .16 & -.06 & .10 & .12 & .06 & .15 & -.02 & -.26 & -.34 & -.37 & -- & \\
\hline 15 Agency & 1.07 & 1.19 & .46 & .27 & .28 & -.11 & .20 & -.08 & -.09 & -.05 & -.04 & .11 & .61 & .68 & .41 & -.23 & -- \\
\hline 16 Communion & 1.51 & 1.24 & .32 & .19 & .14 & -.19 & .16 & .04 & -.07 & .04 & -.02 & .10 & .52 & .58 & .32 & -.22 & .55 \\
\hline
\end{tabular}


Table 3

Descriptive Statistics and Bivariate Correlations for Sample 1, Memory 3

\begin{tabular}{|c|c|c|c|c|c|c|c|c|c|c|c|c|c|c|c|c|c|}
\hline & $M$ & $S D$ & 1 & 2 & 3 & 4 & 5 & 6 & 7 & 8 & 9 & 10 & 11 & 12 & 13 & 14 & 15 \\
\hline 1 Growth & 1.26 & 0.70 & -- & & & & & & & & & & & & & & \\
\hline 2 Exploratory Processing & 1.66 & 0.82 & .60 & -- & & & & & & & & & & & & & \\
\hline 3 Meaning-making & 0.66 & 1.14 & .52 & .56 & -- & & & & & & & & & & & & \\
\hline 4 Stability Connections & 0.57 & 0.57 & -.17 & -.09 & -.15 & -- & & & & & & & & & & & \\
\hline 5 Change Connections & 0.55 & 0.61 & .36 & .47 & .43 & -.25 & -- & & & & & & & & & & \\
\hline 6 Facts & 1.90 & 0.85 & -.22 & -.28 & -.17 & .08 & -.20 & -- & & & & & & & & & \\
\hline 7 Interpretations & 1.76 & 0.67 & .16 & .32 & .21 & .14 & .26 & .15 & -- & & & & & & & & \\
\hline 8 Contextual Coherence & 2.37 & 0.65 & -.03 & .01 & -.03 & -.01 & -.01 & .36 & .16 & -- & & & & & & & \\
\hline 9 Chronologic Coherence & 2.77 & 0.54 & -.07 & -.03 & -.03 & -.02 & -.09 & .35 & .08 & .36 & -- & & & & & & \\
\hline 10 Thematic Coherence & 2.14 & 0.75 & .31 & .39 & .38 & .04 & .35 & .08 & .45 & .12 & -.07 & -- & & & & & \\
\hline 11 Affective Tone & 2.46 & 0.80 & .30 & .14 & .10 & -.09 & .04 & -.05 & -.15 & -.16 & -.04 & -.02 & -- & & & & \\
\hline 12 Ending Valence & 2.16 & 1.49 & .48 & .30 & .20 & -.08 & .17 & -.14 & .02 & -.12 & -.06 & .13 & .74 & -- & & & \\
\hline 13 Redemptive & 0.22 & 0.42 & .34 & .27 & .25 & -.11 & .17 & -.03 & .09 & -.02 & .04 & .28 & .34 & .46 & -- & & \\
\hline 14 Contamination & 0.32 & 0.47 & -.18 & -.13 & -.08 & .05 & -.03 & .14 & .10 & .11 & .09 & -.01 & -.29 & -.31 & -.37 & -- & \\
\hline 15 Agency & 1.24 & 1.25 & .43 & .27 & .23 & -.04 & .13 & -.07 & -.07 & -.12 & -.03 & .18 & .69 & .73 & .40 & -.29 & -- \\
\hline 16 Communion & 1.53 & 1.23 & .22 & .10 & .10 & -.11 & .04 & .09 & -.06 & -.05 & -.02 & .11 & .49 & .48 & .27 & -.14 & .50 \\
\hline
\end{tabular}


Table 4

Descriptive Statistics and Bivariate Correlations for Sample 2

\begin{tabular}{|c|c|c|c|c|c|c|c|c|c|c|c|c|c|c|c|c|c|}
\hline & $M$ & $S D$ & 1 & 2 & 3 & 4 & 5 & 6 & 7 & 8 & 9 & 10 & 11 & 12 & 13 & 14 & 15 \\
\hline 1 Growth & 2.36 & 1.17 & -- & & & & & & & & & & & & & & \\
\hline 2 Exploratory Processing & 2.18 & 0.98 & .51 & -- & & & & & & & & & & & & & \\
\hline 3 Meaning-making & 1.30 & 1.31 & .45 & .50 & -- & & & & & & & & & & & & \\
\hline 4 Stability Connections & 0.65 & 0.54 & -.12 & .00 & .00 & -- & & & & & & & & & & & \\
\hline 5 Change Connections & 0.71 & 0.59 & .41 & .34 & .27 & -.29 & -- & & & & & & & & & & \\
\hline 6 Facts & 2.00 & 0.81 & -.07 & .03 & -.02 & .04 & .02 & -- & & & & & & & & & \\
\hline 7 Interpretations & 2.23 & 0.69 & .36 & .48 & .41 & .06 & .23 & .14 & -- & & & & & & & & \\
\hline 8 Contextual Coherence & 1.99 & 1.01 & -.01 & .07 & .01 & .06 & .00 & .42 & .02 & -- & & & & & & & \\
\hline 9 Chronologic Coherence & 2.05 & 1.06 & .00 & .03 & .04 & .08 & .06 & .52 & .13 & .35 & -- & & & & & & \\
\hline 10 Thematic Coherence & 1.61 & 0.73 & .41 & .43 & .45 & .07 & .22 & .05 & .32 & .09 & .09 & -- & & & & & \\
\hline 11 Affective Tone & 3.06 & 1.04 & .10 & -.08 & -.10 & .12 & -.08 & -.10 & -.07 & .04 & -.09 & .01 & -- & & & & \\
\hline 12 Ending Valence & 3.49 & 1.50 & .33 & .05 & .01 & .13 & .01 & -.05 & .00 & .04 & -.02 & .13 & .73 & -- & & & \\
\hline 13 Redemptive & 0.32 & 0.47 & .36 & .27 & .26 & .00 & .18 & .05 & .23 & .02 & .03 & .23 & .01 & .18 & -- & & \\
\hline 14 Contamination & 0.14 & 0.35 & -.17 & -.05 & -.02 & -.13 & .03 & .09 & .09 & .01 & .05 & .00 & -.42 & -.47 & -.13 & -- & \\
\hline 15 Agency & 1.78 & 1.33 & .23 & .10 & .06 & .11 & .08 & -.01 & .07 & .03 & .04 & .07 & .27 & .32 & .04 & -.18 & -- \\
\hline 16 Communion & 2.12 & 1.44 & -.01 & -.09 & -.07 & -.01 & -.05 & .04 & -.05 & .01 & .00 & -.01 & .50 & .41 & .07 & -.24 & .13 \\
\hline
\end{tabular}

Note. Values are based on mean values across narratives. 
Table 5

Descriptive Statistics and Bivariate Correlations for Sample 3

\begin{tabular}{|c|c|c|c|c|c|c|c|c|c|c|c|c|c|c|c|c|c|}
\hline & $M$ & $S D$ & 1 & 2 & 3 & 4 & 5 & 6 & 7 & 8 & 9 & 10 & 11 & 12 & 13 & 14 & 15 \\
\hline 1 Growth & 1.89 & 1.05 & -- & & & & & & & & & & & & & & \\
\hline 2 Exploratory Processing & 2.18 & 0.95 & .55 & -- & & & & & & & & & & & & & \\
\hline 3 Meaning-making & 0.82 & 1.20 & .60 & .43 & -- & & & & & & & & & & & & \\
\hline 4 Stability Connections & 0.74 & 0.53 & -.20 & -.06 & -.24 & -- & & & & & & & & & & & \\
\hline 5 Change Connections & 0.76 & 0.66 & .43 & .44 & .42 & -.35 & -- & & & & & & & & & & \\
\hline 6 Facts & 1.88 & 0.88 & -.19 & -.10 & -.14 & .04 & -.15 & -- & & & & & & & & & \\
\hline 7 Interpretations & 1.89 & 0.65 & .23 & .43 & .18 & .03 & .16 & -.03 & -- & & & & & & & & \\
\hline 8 Contextual Coherence & 2.60 & 0.67 & -.11 & .03 & -.07 & .06 & -.05 & .53 & .09 & -- & & & & & & & \\
\hline 9 Chronologic Coherence & 2.90 & 0.37 & .12 & .12 & .12 & -.10 & .08 & .28 & .15 & .26 & -- & & & & & & \\
\hline 10 Thematic Coherence & 1.93 & 0.80 & .35 & .47 & .19 & -.06 & .27 & .25 & .56 & .22 & .20 & -- & & & & & \\
\hline 11 Affective Tone & 3.03 & 1.14 & .14 & -.04 & -.05 & -.02 & -.06 & -.02 & -.09 & -.01 & .10 & -.03 & -- & & & & \\
\hline 12 Ending Valence & 3.48 & 1.58 & .39 & .10 & .13 & -.06 & .08 & -.09 & -.05 & -.04 & .08 & .03 & .79 & -- & & & \\
\hline 13 Redemptive & 0.13 & 0.32 & .30 & .23 & .23 & -.02 & .19 & -.17 & .08 & -.08 & .02 & .10 & .03 & .16 & -- & & \\
\hline 14 Contamination & 0.10 & 0.28 & -.09 & .04 & .00 & -.06 & .06 & -.02 & .08 & -.04 & .04 & .00 & -.28 & -.33 & -.06 & -- & \\
\hline 15 Agency & 2.02 & 1.52 & .28 & .09 & .09 & -.01 & .07 & -.11 & .02 & -.03 & .09 & .05 & .69 & .68 & .15 & -.23 & -- \\
\hline 16 Communion & 2.08 & 1.18 & .11 & -.10 & .01 & -.02 & -.08 & .05 & -.05 & .04 & .15 & -.05 & .60 & .57 & -.01 & -.21 & .47 \\
\hline
\end{tabular}

Note. Values are based on mean values across narratives. 
Table 6

Model Fit Estimates for all Factor Analytic Models

\begin{tabular}{|c|c|c|c|c|c|c|c|}
\hline \multirow[b]{2}{*}{ Model } & & \multirow[b]{2}{*}{$\chi^{2}$} & \multirow[b]{2}{*}{$d \mathrm{f}$} & \multicolumn{4}{|c|}{ RMSE } \\
\hline & & & & $p$ & CFI & $\mathrm{A}$ & $90 \% \mathrm{CI}$ \\
\hline 1 & Sample 1 EFA & 235.54 & 75 & $<.001$ & .96 & .06 & $.054, .072$ \\
\hline 2 & Sample 1 EFA 2 & 164.91 & 63 & $<.001$ & .97 & .05 & $.044, .065$ \\
\hline 3 & Sample 1, Memory 1 CFA (L) & 225.73 & 82 & $<.001$ & .96 & .06 & $.048, .066$ \\
\hline 4 & Sample 1, Memory 2 CFA (L) & 247.28 & 82 & $<.001$ & .96 & .06 & $.052, .070$ \\
\hline 5 & Sample 1, Memory 2 CFA (L) & 298.10 & 82 & $<.001$ & .95 & .07 & $.061, .078$ \\
\hline 6 & Sample 2 CFA (L) & 138.56 & 82 & $<.001$ & .98 & .04 & $.027, .049$ \\
\hline 7 & Sample 3 CFA (L) & 223.80 & 82 & $<.001$ & .96 & .06 & $.053, .073$ \\
\hline 8 & Sample 1, Memory 1 (F) & 93.74 & 32 & $<.001$ & .94 & .06 & $.046, .074$ \\
\hline 9 & Sample 1, Memory $2(\mathrm{~F})$ & 68.40 & 32 & 0.0002 & .97 & .05 & $.031, .061$ \\
\hline 10 & Sample 1, Memory $2(\mathrm{~F})$ & 113.15 & 32 & $<.001$ & .93 & .07 & $.055, .082$ \\
\hline 11 & Sample $2(F)$ & 44.76 & 32 & 0.067 & .98 & .03 & $.000, .048$ \\
\hline 12 & Sample $3(\mathrm{~F})$ & 90.53 & 32 & $<.001$ & .92 & .07 & $.049, .081$ \\
\hline 13 & Sample 1, Low Point (L) & 192.49 & 82 & $<.001$ & .79 & .07 & $.054, .078$ \\
\hline 14 & Sample 1, Self-Defining (L) & 232.54 & 82 & $<.001$ & .87 & .07 & $.062, .085$ \\
\hline 15 & Sample 1, Transgression (L) & 156.65 & 82 & $<.001$ & .81 & .05 & $.040, .065$ \\
\hline 16 & Sample 1, Trauma (L) & 199.66 & 82 & $<.001$ & .85 & .07 & $.054, .078$ \\
\hline 17 & Sample 1, Turning Point (L) & 235.61 & 82 & $<.001$ & .83 & .08 & $.064, .086$ \\
\hline 18 & Sample $2+3$, High Point (L) & 178.35 & 82 & $<.001$ & .88 & .06 & $.050, .075$ \\
\hline $18 \mathrm{a}$ & $\begin{array}{l}\text { Sample } 2+3 \text {, High Point, Reduced } \\
\text { (L) }\end{array}$ & 132.08 & 69 & $<.002$ & .89 & .06 & $.041, .069$ \\
\hline 19 & Sample 2 + 3, Low Point (L) & 126.21 & 82 & $<.001$ & .89 & .04 & $.027, .056$ \\
\hline 20 & Sample $2+3$, Turning Point (L) & 119.90 & 82 & $<.001$ & .91 & .04 & $.023, .054$ \\
\hline 21 & Sample 1, Low Point (F) & 81.42 & 32 & $<.001$ & .84 & .07 & $.051, .089$ \\
\hline 22 & Sample 1, Self-Defining (F) & 56.08 & 32 & 0.005 & .96 & .05 & $.025, .067$ \\
\hline 23 & Sample 1, Transgression (F) & 77.16 & 32 & $<.001$ & .83 & .07 & $.047, .085$ \\
\hline 24 & Sample 1, Trauma $(\mathrm{F})$ & 80.36 & 32 & $<.001$ & .90 & .07 & $.049, .086$ \\
\hline 25 & Sample 1, Turning Point (F) & 88.86 & 32 & $<.001$ & .91 & .07 & $.055, .091$ \\
\hline 26 & Sample 2 + 3, High Point (F) & 94.53 & 32 & $<.001$ & .89 & .08 & $.062, .100$ \\
\hline $26 \mathrm{a}$ & $\begin{array}{l}\text { Sample } 2+3 \text {, High Point, Reduced } \\
\text { (F) }\end{array}$ & 26.81 & 17 & 0.061 & .97 & .04 & $.000, .074$ \\
\hline 27 & Sample $2+3$, Low Point $(\mathrm{F})$ & 54.26 & 32 & 0.008 & .92 & .05 & $.024, .069$ \\
\hline 28 & Sample $2+3$, Turning Point $(\mathrm{F})$ & 52.16 & 32 & 0.014 & .90 & .05 & $.021, .067$ \\
\hline
\end{tabular}

Note. $(\mathrm{L})=$ Landscape Model, $(\mathrm{F})=$ Functional Model 
The Structure of Narrative Identity 72

Table 7

Standardized Factor Loadings for All Landscape Models

\begin{tabular}{|c|c|c|c|c|c|c|c|c|c|c|c|c|c|}
\hline Model \# & 3 & 4 & 5 & 6 & 7 & 13 & 14 & 15 & 16 & 17 & $18 \mathrm{a}$ & 19 & 20 \\
\hline Sample and Prompt & 1.1 & 1.2 & 1.3 & 2 & 3 & 1-LP & 1-SD & $1-\mathrm{TG}$ & $1-\mathrm{TM}$ & $1-\mathrm{TP}$ & $2+3-\mathrm{HP}$ & 2+3-LP & $2+3-\mathrm{TP}$ \\
\hline \multicolumn{14}{|l|}{ Autobiographical Reasoning } \\
\hline Exploratory Processing & .84 & .88 & .88 & .77 & .79 & .74 & .88 & .73 & .82 & .89 & .88 & .78 & .82 \\
\hline Growth & .76 & .80 & .82 & .81 & .87 & .40 & .62 & .42 & .38 & .60 & .73 & .74 & .64 \\
\hline Meaning & .82 & .86 & .82 & .64 & .77 & .86 & .82 & .65 & .82 & .80 & .73 & .63 & .51 \\
\hline Interpretations & .43 & .54 & .54 & .56 & .42 & .42 & .50 & .61 & .55 & .51 & .54 & .51 & .57 \\
\hline Change Connections & .73 & .74 & .69 & .54 & .67 & .68 & .71 & .49 & .76 & .72 & .54 & .53 & .41 \\
\hline Thematic Coherence & .77 & .79 & .75 & .60 & .65 & .50 & .73 & .72 & .62 & .69 & .55 & .52 & .55 \\
\hline Redemption & .45 & .40 & .34 & .54 & .47 & .28 & .26 & .29 & .13 & .24 & .23 & .54 & .27 \\
\hline Valence & .31 & .21 & .13 & .18 & .19 & .35 & .09 & .24 & .27 & .15 & -.11 & .47 & .15 \\
\hline \multicolumn{14}{|l|}{ Structure } \\
\hline Context Coherence & .52 & .49 & .57 & .58 & .77 & .38 & .43 & .63 & .51 & .62 & .75 & .78 & .76 \\
\hline Chronological Coherence & .46 & .52 & .61 & .74 & .55 & .31 & .59 & .57 & .69 & .50 & .73 & .82 & .63 \\
\hline Thematic Coherence & .35 & .36 & .26 & .10 & .56 & .23 & .31 & .29 & .23 & .16 & .30 & .31 & .34 \\
\hline Facts & .56 & .77 & .78 & .84 & .88 & .92 & .70 & .75 & .78 & .74 & .72 & .58 & .50 \\
\hline Interpretations & .47 & .60 & .47 & .14 & .22 & .31 & .60 & .39 & .32 & .39 & .01 & .05 & .02 \\
\hline \multicolumn{14}{|l|}{$\begin{array}{l}\text { Motivational and Affective } \\
\text { Themes }\end{array}$} \\
\hline Redemption & .56 & .52 & .52 & .20 & .17 & .51 & .64 & .37 & .66 & .51 & -.17 & .43 & .12 \\
\hline Contamination & -.46 & -.55 & -.51 & -.79 & -.56 & -.23 & -.97 & -.21 & -.58 & -.98 & -- & -.10 & -.28 \\
\hline Valence & .81 & .89 & .94 & .93 & .96 & .63 & .79 & .60 & .68 & .81 & .20 & .52 & .83 \\
\hline Tone & .81 & .79 & .86 & .86 & .88 & .53 & .68 & .70 & .60 & .70 & .18 & .63 & .81 \\
\hline Agency & .75 & .77 & .82 & .33 & .74 & .62 & .72 & .55 & .52 & .76 & .91 & .32 & .31 \\
\hline Communion & .56 & .65 & .55 & .50 & .66 & .28 & .59 & .51 & .27 & .47 & -.04 & .32 & .47 \\
\hline Growth & .46 & .42 & .44 & .30 & .35 & .23 & .27 & .34 & .27 & .39 & -.07 & .37 & .34 \\
\hline \multicolumn{14}{|l|}{ Factor Correlations } \\
\hline AR with ST & -.19 & -.35 & -.32 & .04 & -.20 & -.23 & -.27 & -.25 & -.09 & -.24 & .12 & -.01 & -.15 \\
\hline AR with MAT & .24 & .29 & .21 & -.10 & -.06 & .05 & .16 & -.23 & .01 & .23 & .21 & -.16 & .01 \\
\hline MAT with ST & -.22 & -.23 & -.20 & -.06 & -.01 & .07 & -.24 & .12 & -.15 & -.38 & .29 & -.15 & -.04 \\
\hline
\end{tabular}

Note: See Table 6 to link model\# to model details. LP = Low Point; SD = Self-Defining; TG = Transgression; TM = Trauma; TP = Turning Point; HP = High Point; $\mathrm{AR}=$ Autobiographical Reasoning; $\mathrm{ST}=$ Structure; $\mathrm{MAT}=$ Motivational and Affective Themes. 
The Structure of Narrative Identity 73

Table 8

Standardized Factor Loadings for All Functional Models

\begin{tabular}{|c|c|c|c|c|c|c|c|c|c|c|c|c|c|}
\hline Model \# & 8 & 9 & 10 & 11 & 12 & 21 & 22 & 23 & 24 & 25 & $26 a$ & 27 & 28 \\
\hline Sample and Prompt & 1.1 & 1.2 & 1.3 & 2 & 3 & 1-LP & $1-\mathrm{SD}$ & $1-\mathrm{TG}$ & $1-\mathrm{TM}$ & $1-\mathrm{TP}$ & 2+3-HP & 2+3-LP & $2+3-\mathrm{TP}$ \\
\hline \multicolumn{14}{|l|}{ Autobiographical Reasoning } \\
\hline Exploratory Processing & .80 & .84 & .86 & .82 & .69 & .72 & .88 & .62 & .77 & .87 & .87 & .74 & .94 \\
\hline Meaning & .86 & .87 & .83 & .62 & .79 & .84 & .85 & .62 & .90 & .80 & .73 & .59 & .43 \\
\hline Change Connections & .72 & .74 & .70 & .51 & .75 & .74 & .70 & .59 & .75 & .72 & .53 & .60 & .42 \\
\hline \multicolumn{14}{|l|}{ Structure } \\
\hline Context Coherence & .59 & .50 & .56 & .58 & .71 & .39 & .40 & .59 & .58 & .67 & .74 & .79 & .80 \\
\hline Chronological Coherence & .53 & .52 & .67 & .72 & .53 & .39 & .55 & .67 & .73 & .53 & .71 & .82 & .60 \\
\hline Facts & .57 & .93 & .80 & .85 & .88 & .95 & .78 & .72 & .72 & .74 & .75 & .58 & .50 \\
\hline \multicolumn{14}{|l|}{$\begin{array}{l}\text { Motivational and Affective } \\
\text { Themes }\end{array}$} \\
\hline Contamination & -.40 & -.50 & -.49 & -.68 & -.53 & -.06 & -.57 & -.16 & -.26 & -.68 & -- & -.02 & -.26 \\
\hline Tone & .79 & .76 & .82 & .85 & .94 & .56 & .87 & .68 & .97 & .82 & .49 & .65 & .84 \\
\hline Agency & .79 & .83 & .89 & .27 & .71 & .66 & .81 & .65 & .35 & .84 & -- & .34 & .25 \\
\hline Communion & .58 & .67 & .55 & .52 & .65 & .34 & .73 & .45 & .25 & .55 & .35 & .33 & .52 \\
\hline \multicolumn{14}{|l|}{ Factor Correlations } \\
\hline AR with ST & -.23 & -.33 & -.31 & .06 & -.15 & -.26 & -.31 & -.30 & -.11 & -.24 & .19 & -.02 & -.03 \\
\hline AR with MAT & .26 & .35 & .25 & -.10 & -.04 & .03 & .14 & -.24 & -.03 & .24 & -.21 & -.04 & .06 \\
\hline MAT with ST & -.18 & -.14 & -.15 & -.07 & .03 & .06 & -.26 & .11 & -.25 & -.33 & .07 & -.21 & -.02 \\
\hline
\end{tabular}

Note: See Table 6 to link model\# to model details. LP = Low Point; SD = Self-Defining; TG = Transgression; TM = Trauma; TP = Turning Point; HP = High Point; $\mathrm{AR}=$ Autobiographical Reasoning; ST $=$ Structure; MAT = Motivational and Affective Themes. 
Table 9

Path Analytic Estimates of Narrative Identity Factors Predicting Outcomes: WWU Landscape Models with Latent Well-Being

\begin{tabular}{|c|c|c|c|c|c|c|c|c|c|c|c|c|}
\hline \multirow[t]{2}{*}{$\begin{array}{l}\text { Model \# } \\
\text { Sample and Prompt }\end{array}$} & \multicolumn{4}{|c|}{41} & \multicolumn{4}{|c|}{43} & \multicolumn{4}{|c|}{45} \\
\hline & $b$ & $S E$ & $\beta$ & $p$ & $b$ & $S E$ & $\beta$ & $p$ & $b$ & $S E$ & $\beta$ & $p$ \\
\hline \multicolumn{13}{|l|}{ GPA } \\
\hline $\mathrm{AR}$ & 0.01 & 0.03 & -0.01 & .97 & 0.06 & 0.04 & 0.09 & .11 & -0.03 & 0.03 & -0.04 & .42 \\
\hline ST & 0.11 & 0.07 & 0.11 & .11 & 0.11 & 0.07 & 0.10 & .09 & 0.04 & 0.06 & 0.04 & .50 \\
\hline MAT & -0.01 & 0.05 & -0.01 & .81 & 0.01 & 0.06 & -0.01 & .97 & 0.02 & 0.03 & 0.04 & .40 \\
\hline \multicolumn{13}{|l|}{ Latent Well-Being } \\
\hline $\mathrm{AR}$ & 0.52 & 0.48 & 0.07 & .28 & 0.28 & 0.44 & 0.04 & .52 & 0.04 & 0.38 & 0.01 & .92 \\
\hline ST & 0.68 & 0.88 & 0.05 & .44 & 0.16 & 0.80 & 0.01 & .84 & 1.01 & 0.68 & 0.10 & .14 \\
\hline MAT & 4.43 & 0.84 & 0.37 & $<.001$ & 3.33 & 0.85 & 0.27 & $<.001$ & 1.59 & 0.34 & 0.29 & $<.001$ \\
\hline
\end{tabular}

Note. See Table 6 to link model\# to model details. AR = Autobiographical Reasoning; ST = Structure; MAT = Motivational and

Affective Themes. All outcomes were included in a single path model. Bolded entries are significant at $p<.05$

Table 10

Path Analytic Estimates of Narrative Identity Factors Predicting Outcomes: WWU Functional Models with Latent Well-Being

\begin{tabular}{|c|c|c|c|c|c|c|c|c|c|c|c|c|}
\hline \multirow{2}{*}{$\begin{array}{l}\text { Model \# } \\
\text { Sample and Prompt }\end{array}$} & \multicolumn{4}{|c|}{42} & \multicolumn{4}{|c|}{44} & \multicolumn{4}{|c|}{$\begin{array}{c}46 \\
\text { Sample 1, Memory } 3\end{array}$} \\
\hline & $b$ & $S E$ & $\beta$ & $p$ & $b$ & $S E$ & $\beta$ & $p$ & $b$ & $S E$ & $\beta$ & $p$ \\
\hline \multicolumn{13}{|l|}{ GPA } \\
\hline $\mathrm{AR}$ & 0.01 & 0.04 & 0.01 & .83 & 0.05 & 0.04 & 0.07 & .27 & -0.05 & 0.05 & -0.06 & .32 \\
\hline ST & 0.10 & 0.06 & 0.11 & .13 & 0.11 & 0.07 & 0.09 & .11 & 0.00 & 0.09 & 0.01 & .99 \\
\hline MAT & -0.02 & 0.03 & -0.03 & .55 & -0.02 & 0.03 & -0.04 & .48 & 0.02 & 0.03 & 0.05 & .37 \\
\hline \multicolumn{13}{|l|}{ Latent Well-Being } \\
\hline AR & 0.52 & 0.58 & 0.06 & .38 & 0.06 & 0.56 & 0.01 & .92 & 0.35 & 0.74 & 0.03 & .64 \\
\hline ST & 0.29 & 0.84 & 0.03 & .73 & -0.59 & 0.85 & -0.04 & .49 & 1.12 & 1.54 & 0.05 & .47 \\
\hline MAT & 3.05 & 0.56 & 0.39 & $<.001$ & 2.12 & 0.51 & 0.29 & $<.001$ & 1.64 & 0.42 & 0.24 & $<.001$ \\
\hline
\end{tabular}

Note. See Table 6 to link model\# to model details. AR = Autobiographical Reasoning; ST $=$ Structure; MAT $=$ Motivational and

Affective Themes. All outcomes were included in a single path model. Bolded entries are significant at $p<.05$ 
Table 11

Path Analytic Estimates of Narrative Identity Factors Predicting Outcomes: WWU Landscape Models

Model \# $\quad 29 \quad 31 \quad 33$

Sample and Prompt

Sample 1, Memory 1

Sample 1, Memory 2

33

$\begin{array}{rrrrrrrrrrrrrr}b & S E & \beta & p & & b & S E & \beta & p & & b & S E & \beta & p \\ -0.01 & 0.03 & -0.01 & .97 & & 0.06 & 0.04 & 0.09 & .11 & & -0.03 & 0.03 & -0.04 & .42 \\ 0.11 & 0.07 & 0.11 & .11 & & 0.11 & 0.07 & 0.10 & .10 & & 0.04 & 0.06 & 0.04 & .50 \\ -0.01 & 0.05 & -0.01 & .81 & & 0.00 & 0.03 & 0.00 & .97 & & 0.02 & 0.03 & 0.04 & .40\end{array}$

Depressive Symptoms

$\begin{array}{lrlllllllllll}\text { AR } & \mathbf{1 . 3 0} & \mathbf{0 . 6 3} & \mathbf{0 . 1 1} & \mathbf{. 0 4} & 0.76 & 0.61 & 0.07 & .21 & 0.20 & 0.62 & 0.02 & .75 \\ \text { ST } & 0.52 & 1.21 & 0.03 & .67 & -0.59 & 1.11 & -0.03 & .59 & 0.02 & 1.03 & 0.00 & .99 \\ & & & & <.00 & & & & & & & & \\ \text { MAT } & \mathbf{- 3 . 8 5} & \mathbf{1 . 0 0} & \mathbf{- 0 . 2 1} & \mathbf{1} & \mathbf{- 1 . 3 0} & \mathbf{0 . 5 6} & \mathbf{- 0 . 1 2} & \mathbf{. 0 2} & -0.87 & 0.46 & -0.09 & .06\end{array}$

PILL

$\begin{array}{lrrrrrrrrrrrr}\text { AR } & 0.41 & 0.65 & 0.03 & .53 & 0.61 & 0.63 & 0.05 & .33 & \mathbf{1 . 3 8} & \mathbf{0 . 6 1} & \mathbf{0 . 1 2} & \mathbf{. 0 2} \\ & & & & & & & & & & & & <.00 \\ \text { ST } & 0.69 & 1.15 & 0.03 & .55 & 0.86 & 1.18 & 0.04 & .47 & \mathbf{3 . 2 7} & \mathbf{1 . 1 3} & \mathbf{0 . 1 7} & \mathbf{1} \\ \text { MAT } & \mathbf{- 2 . 7 3} & \mathbf{1 . 0 4} & \mathbf{- 0 . 1 4} & \mathbf{. 0 1} & -0.79 & 0.59 & -0.07 & .18 & -0.86 & 0.50 & -0.08 & .08\end{array}$

Positive Affect

$\begin{array}{lrrrrrrrrrrrr}\text { AR } & 0.07 & 0.05 & 0.09 & .11 & 0.08 & 0.05 & 0.09 & .11 & \mathbf{0 . 1 1} & \mathbf{0 . 0 4} & \mathbf{0 . 1 3} & \mathbf{. 0 1} \\ \text { ST } & -0.04 & 0.08 & -0.03 & .66 & -0.07 & 0.08 & -0.05 & .36 & \mathbf{- 0 . 1 5} & \mathbf{0 . 0 7} & \mathbf{- 0 . 1 1} & \mathbf{. 0 5} \\ & & & & <.00 & & & & <.00 & & & <.00 \\ \text { MAT } & \mathbf{0 . 2 3} & \mathbf{0 . 0 7} & \mathbf{0 . 1 7} & \mathbf{1} & \mathbf{0 . 1 6} & \mathbf{0 . 0 4} & \mathbf{0 . 2 0} & \mathbf{1} & \mathbf{0 . 1 5} & \mathbf{0 . 0 3} & \mathbf{0 . 2 1} & \mathbf{1}\end{array}$

Negative Affect

\begin{tabular}{|c|c|c|c|c|c|c|c|c|c|c|c|c|}
\hline AR & 0.03 & 0.04 & 0.04 & .40 & 0.04 & 0.03 & 0.06 & .18 & 0.02 & 0.03 & 0.03 & .47 \\
\hline ST & 0.10 & 0.07 & 0.09 & .15 & 0.06 & 0.07 & 0.05 & .35 & 0.02 & 0.06 & 0.02 & \\
\hline MAT & -0.30 & 0.06 & -0.27 & $\begin{array}{l}<.00 \\
1\end{array}$ & -0.15 & 0.04 & -0.23 & $\begin{array}{l}<.00 \\
1\end{array}$ & -0.18 & 0.03 & -0.31 & $<.00$ \\
\hline \multicolumn{13}{|c|}{ fe Satisfaction } \\
\hline AR & -0.08 & 0.08 & -0.05 & .30 & 0.02 & 0.08 & 0.02 & .76 & 0.05 & 0.08 & 0.03 & .56 \\
\hline $\mathrm{ST}$ & 0.08 & 0.14 & 0.04 & .57 & 0.20 & 0.14 & 0.08 & .15 & 0.01 & 0.12 & 0.01 & .92 \\
\hline
\end{tabular}

Note. See Table 6 to link model\# to model details. AR = Autobiographical Reasoning; ST = Structure; MAT =

Motivational and Affective Themes. All outcomes were included in a single path model. Bolded entries are significant at $p<.05$ 
Table 12

Path Analytic Estimates of Narrative Identity Factors Predicting Outcomes: WWU Functional Models

\begin{tabular}{|c|c|c|c|c|c|c|c|c|c|c|c|c|}
\hline \multirow[t]{2}{*}{$\begin{array}{l}\text { Model \# } \\
\text { Sample and Prompt }\end{array}$} & \multicolumn{4}{|c|}{$\begin{array}{c}30 \\
\text { Sample 1, Memory } 1\end{array}$} & \multicolumn{4}{|c|}{$\begin{array}{c}32 \\
\text { Sample 1, Memory } 2\end{array}$} & \multicolumn{4}{|c|}{$\begin{array}{c}34 \\
\text { Sample 1, Memory } 3\end{array}$} \\
\hline & $b$ & $S E$ & $\beta$ & $p$ & $b$ & $S E$ & $\beta$ & $p$ & $b$ & $S E$ & $\beta$ & $p$ \\
\hline \multicolumn{13}{|l|}{ GPA } \\
\hline AR & 0.01 & 0.04 & 0.01 & .83 & 0.05 & 0.04 & 0.07 & .26 & -0.05 & 0.05 & -0.06 & .32 \\
\hline ST & 0.10 & 0.06 & 0.11 & .13 & 0.10 & 0.07 & 0.10 & .11 & 0.00 & 0.10 & 0.00 & .98 \\
\hline MAT & -0.02 & 0.03 & -0.03 & .55 & -0.02 & 0.03 & -0.04 & .49 & 0.02 & 0.03 & 0.05 & .36 \\
\hline \multicolumn{13}{|c|}{ Depressive Symptoms } \\
\hline AR & 1.17 & 0.71 & 0.09 & .10 & 0.32 & 0.69 & 0.03 & .64 & 0.09 & 0.87 & 0.01 & .92 \\
\hline ST & 0.17 & 1.06 & 0.01 & $\begin{array}{r}.87 \\
<.00\end{array}$ & -1.37 & 1.02 & -0.07 & .18 & -0.65 & 1.79 & -0.02 & .72 \\
\hline MAT & -2.56 & 0.65 & -0.23 & 1 & -1.42 & 0.59 & -0.13 & .02 & -0.77 & 0.47 & -0.08 & .10 \\
\hline \multicolumn{13}{|l|}{ PILL } \\
\hline $\mathrm{AR}$ & 0.25 & 0.77 & 0.02 & .75 & 0.15 & 0.84 & 0.01 & .86 & 1.28 & 0.92 & 0.08 & .16 \\
\hline ST & 0.13 & 1.03 & 0.01 & .90 & 0.13 & 1.17 & 0.01 & .91 & 4.41 & 2.08 & 0.15 & .03 \\
\hline MAT & -1.60 & 0.64 & -0.14 & .01 & -0.81 & 0.59 & -0.07 & .17 & -0.89 & 0.49 & -0.09 & .07 \\
\hline \multicolumn{13}{|l|}{ Positive Affect } \\
\hline $\mathrm{AR}$ & 0.10 & 0.05 & 0.11 & .07 & 0.08 & 0.06 & 0.09 & .18 & 0.09 & 0.06 & 0.08 & .16 \\
\hline ST & 0.01 & 0.08 & 0.01 & $\begin{array}{r}.94 \\
<.00\end{array}$ & -0.04 & 0.08 & -0.03 & $\begin{array}{r}.62 \\
<.00\end{array}$ & -0.25 & 0.12 & -0.12 & $\begin{array}{r}.04 \\
<.00\end{array}$ \\
\hline MAT & 0.15 & 0.05 & 0.18 & 1 & 0.17 & 0.05 & 0.22 & 1 & 0.17 & 0.03 & 0.25 & 1 \\
\hline \multicolumn{13}{|l|}{ Negative Affect } \\
\hline $\mathrm{AR}$ & 0.04 & 0.04 & 0.05 & .38 & 0.03 & 0.04 & 0.05 & .41 & 0.05 & 0.05 & 0.06 & .30 \\
\hline ST & 0.07 & 0.07 & 0.07 & $\begin{aligned} & .29 \\
&<.00\end{aligned}$ & -0.01 & 0.06 & 0.00 & $\begin{array}{r}.94 \\
<.00\end{array}$ & 0.00 & 0.10 & 0.00 & $\begin{array}{r}\quad .98 \\
<.00\end{array}$ \\
\hline MAT & -0.21 & 0.04 & -0.31 & 1 & -0.17 & 0.04 & -0.26 & 1 & -0.17 & $\mathbf{0 . 0 3}$ & -0.31 & 1 \\
\hline \multicolumn{13}{|l|}{ Life Satisfaction } \\
\hline $\mathrm{AR}$ & -0.10 & 0.09 & -0.07 & .25 & 0.03 & 0.09 & 0.02 & .75 & -0.01 & 0.11 & -0.01 & .93 \\
\hline ST & 0.07 & 0.13 & 0.03 & $<\begin{array}{l}.60 \\
<.00\end{array}$ & 0.19 & 0.14 & 0.08 & .15 & -0.17 & 0.21 & -0.05 & .43 \\
\hline MAT & 0.32 & 0.08 & 0.23 & 1 & 0.21 & 0.08 & 0.16 & .01 & 0.07 & 0.06 & 0.06 & .25 \\
\hline
\end{tabular}

Note. See Table 6 to link model\# to model details. AR = Autobiographical Reasoning; ST = Structure; MAT = Motivational and Affective Themes. All outcomes were included in a single path model. Bolded entries are significant at $p<.05$ 
Table 13

Path Analytic Estimates of Narrative Identity Factors Predicting Outcomes: FLSA/NWUG Landscape Models

$\begin{array}{llll}\text { Model \# } & 35 & 37 & 39\end{array}$

Sample and Prompt $\quad$ Sample 2+3, High Point $\quad$ Sample 2+3, Low Point $\quad$ Sample 2+3, Turning Poin

\section{Life Satisfaction}

$b \quad S E$

b $\quad S E$

$\beta \quad p$

b SE $\quad \beta$

$p$

AR

\section{ST}

MAT

$\begin{array}{llll}-0.18 & 0.5 & -0.02 & .75\end{array}$

$0.87 \quad 0.5$

$0.10 \quad .11$

$1.41 \quad 0.8$

$0.21 \quad .00$

$1.97 \quad 0.6$

$2.69 \quad 1.9$

$0.13 \quad .16$

$1.47 \quad 0.9$

8

$\begin{array}{rrrr}0.13 & 0.0 & 0.11 & .16 \\ & 9 & & \end{array}$

$\begin{array}{llll}0.02 & 0.1 & 0.01 & .88\end{array}$

ST

MAT

$\begin{array}{rr}1.07 & 0.3 \\ 9\end{array}$

$0.35 \quad .01$

Conscientiousness

AR

ST

MAT

\section{Extraversion}

AR

ST

MAT

$$
\begin{array}{ll}
-0.03 \quad 0.0 \\
\hline
\end{array}
$$

$-0.03 \quad .71$

$0.08 \quad 0.0$

$0.12 \quad .09$

$0.13 \quad .13$

0.180 .0

0.14 .03

$\begin{array}{llll}0.07 & 0.1 & 0.04 & .56\end{array}$

$\begin{array}{lrrr}0.02 & 0.1 & 0.01 & .87\end{array}$

2

\begin{tabular}{ll}
$0.01 \quad .87$ \\
\hline
\end{tabular}

$0.06 \quad .38$

$\begin{array}{lr} & 9 \\ 0.21 & 0.1\end{array}$

$\begin{array}{llll}0.11 & 0.0 & 0.08 & .19\end{array}$

2

$0.19 \quad .06$

$0.21 \quad 0.1$

$\begin{array}{ll}0.60 & 0.3\end{array}$

2

$0.08 \quad 0.0$

$0.07 \quad .29$

$\begin{array}{llll}0.10 & 0.0 & 0.08 & .22\end{array}$

$0.12 \quad .09$

$\begin{array}{ll}0.39 & 0.5\end{array}$

$0.05 \quad .46$

$3.03 \quad 1.1$

4

\begin{tabular}{ll}
$0.53 \quad 0.4$ \\
\hline
\end{tabular}

0.22 .01

$0.08 \quad .22$

3

(1)

Neuroticism

$\begin{array}{lrrrrrrrrrrrr} & -0.09 & 0.0 & -0.08 & .24 & -0.05 & 0.0 & -0.04 & .52 & -0.11 & 0.0 & -0.09 & .17 \\ \text { AR } & & 8 & & & & 8 & & & & 8 & & \\ & -0.04 & 0.1 & -0.03 & .74 & -0.05 & 0.1 & -0.03 & .69 & -0.10 & 0.1 & -0.05 & .49 \\ \text { ST } & & 0 & & & & 3 & & & & 5 & & \\ & -0.13 & 0.2 & -0.04 & .63 & -0.31 & 0.1 & -0.18 & .06 & -0.09 & 0.0 & -0.10 & .09 \\ \text { MAT } & & 7 & & & & 6 & & & & 6 & & \end{array}$

Openness

\begin{tabular}{lrrrrrrrrrrrr} 
& 0.07 & 0.0 & 0.06 & .36 & $\mathbf{0 . 2 1}$ & $\mathbf{0 . 0}$ & $\mathbf{0 . 1 6}$ & $\mathbf{. 0 1}$ & 0.09 & 0.0 & 0.07 & .32 \\
AR & & 8 & & & & $\mathbf{8}$ & & & & 9 & & \\
& 0.18 & 0.1 & 0.13 & .08 & -0.04 & 0.1 & -0.02 & .79 & 0.00 & 0.1 & 0.00 & .99 \\
ST & & 0 & & & & 3 & & & & 5 & & \\
& -0.27 & 0.2 & -0.09 & .31 & -0.04 & 0.1 & -0.02 & .76 & -0.02 & 0.0 & -0.02 & .72 \\
MAT & & 7 & & & & 3 & & & & 6 & & \\
\hline
\end{tabular}

Note. See Table 6 to link model\# to model details. AR = Autobiographical Reasoning; $\mathrm{ST}=$ Structure; MAT $=$

Motivational and Affective Themes. All outcomes were included in a single path model. Bolded entries are significant at $p<.05$ 
Table 14

Path Analytic Estimates of Narrative Identity Factors Predicting Outcomes: FLSA/NWUG Functional Models

$\begin{array}{lccc}\text { Model \# } & 36 & 38 & 40\end{array}$

Sample and Prompt $\quad$ Sample 2+3, High Point $\quad$ Sample 2+3, Low Point $\quad$ Sample 2+3, Turning Point

\section{Life Satisfaction}

AR

$b \quad S E \quad \beta$

$\begin{array}{lll}b & S E & \beta\end{array}$

$\beta$

\section{ST}

$\begin{array}{llll}-0.11 & 0.6 & -0.01 & .86\end{array}$

$\begin{array}{llll}0.53 & 0.6 & 0.06 & .38\end{array}$

$0.46 \quad 0.6$

$0.05 \quad .46$

$\begin{array}{rr} & 3 \\ 1.93 & 0.7\end{array}$

$0.20 \quad .01$

$\begin{array}{lr}1.16 & 0.8\end{array}$

$0.10 \quad .18$

$2.68 \quad 1.0$

$\begin{array}{ll}0.20 & .01\end{array}$

MAT

$1.27 \quad 1.1$

$0.13 \quad .25$

$\begin{array}{llll}1.00 & 1.2 & 0.09 & .41\end{array}$

$1.02 \quad 0.6$

$0.12 \quad .14$

\section{Agreeableness}

AR

$$
0.18 \quad 0.1
$$

$0.16 \quad .09$

$0.14 \quad 0.0$

$0.12 \quad .12$

$0.10 \quad 0.1$

$0.08 \quad .33$

$\begin{array}{lr}0.00 & 0.1\end{array}$

$0.00 \quad .98$

$\begin{array}{llll}0.07 & 0.1 & 0.04 & .58\end{array}$

$0.15 \quad 0.1$

$0.07 \quad .31$

ST

MAT

$0.55 \quad 0.3$
0

$0.39 \quad .07$

$\begin{array}{llll}0.02 & 0.1 & 0.01 & .90\end{array}$

$0.16 \quad 0.1$

$0.12 \quad .13$

\section{Conscientiousness}

AR

$$
-0.04 \quad 0.0
$$

$-0.03 \quad .69$

$0.04 \quad 0.0$

$0.04 \quad .64$

$0.07 \quad 0.0$

$0.05 \quad .45$

$0.12 \quad 0.0$

$0.09 \quad .19$

$0.22 \quad 0.1$

ST

MAT

\begin{tabular}{ll}
$0.27 \quad 0.2$ \\
\hline
\end{tabular}

$0.19 \quad .17$

3

$0.13 \quad .08$

$0.03 \quad 0.1$

$0.02 \quad .83$

$\begin{array}{llll}0.18 & 0.1 & 0.11 & .31\end{array}$

$0.11 \quad 0.1$
0

$0.09 \quad 27$

\section{Extraversion}

AR

$$
0.09 \quad 0.0
$$

$0.08 \quad .27$

$\begin{array}{llll}0.06 & 0.0 & 0.05 & .50\end{array}$

$0.04 \quad 0.1$

0.1

$0.03 \quad .71$

$\begin{array}{rr}0.10 & 8 \\ 0.1\end{array}$

$0.07 \quad .31$

$\begin{array}{llll}0.08 & 0.1 & 0.04 & .57\end{array}$

$0.17 \quad 0.1$

$0.09 \quad .27$

ST

MAT

$$
\begin{array}{rr}
0.17 \quad 0.1 \\
6
\end{array}
$$

$0.12 \quad .29$

$0.18 \quad 0.2$

$0.11 \quad .35$

$-0.04$

0.0

$-0.04 \quad .62$

\section{Neuroticism}

$\begin{array}{lrrrrrrrrrrrr} & -0.09 & 0.0 & -0.08 & .31 & -0.03 & 0.0 & -0.02 & .75 & -0.14 & 0.1 & -0.11 & .19 \\ \text { AR } & & 9 & & & & 9 & & & & 1 & & \\ & -0.03 & 0.1 & -0.02 & .77 & -0.07 & 0.1 & -0.04 & .57 & -0.10 & 0.1 & -0.05 & .51 \\ \text { ST } & & 1 & & & & 3 & & & & 5 & & \\ & 0.01 & 0.1 & 0.01 & .95 & -0.34 & 0.1 & -0.20 & .06 & -0.10 & 0.0 & -0.08 & .24 \\ \text { MAT } & & 3 & & & & 8 & & & & 8 & & \end{array}$

\section{Openness}

\begin{tabular}{lrrrrrrrrrrrr} 
& 0.02 & 0.0 & 0.01 & .85 & 0.15 & 0.1 & 0.12 & .11 & 0.15 & 0.1 & 0.11 & .16 \\
AR & & 8 & & & & 0 & & & & 1 & & \\
& 0.16 & 0.1 & 0.11 & .14 & -0.07 & 0.1 & -0.04 & .62 & -0.01 & 0.1 & -0.01 & .92 \\
ST & & 1 & & & & 3 & & & & 4 & & \\
& -0.06 & 0.1 & -0.04 & .67 & -0.05 & 0.1 & -0.03 & .74 & 0.02 & 0.0 & 0.01 & .86 \\
MAT & & 3 & & & & 6 & & & & 9 & & \\
\hline
\end{tabular}

Note. See Table 6 to link model\# to model details. AR = Autobiographical Reasoning; $\mathrm{ST}=$ Structure; MAT = Motivational and Affective Themes. All outcomes were included in a single path model. Bolded entries are significant at $p<.05$ 


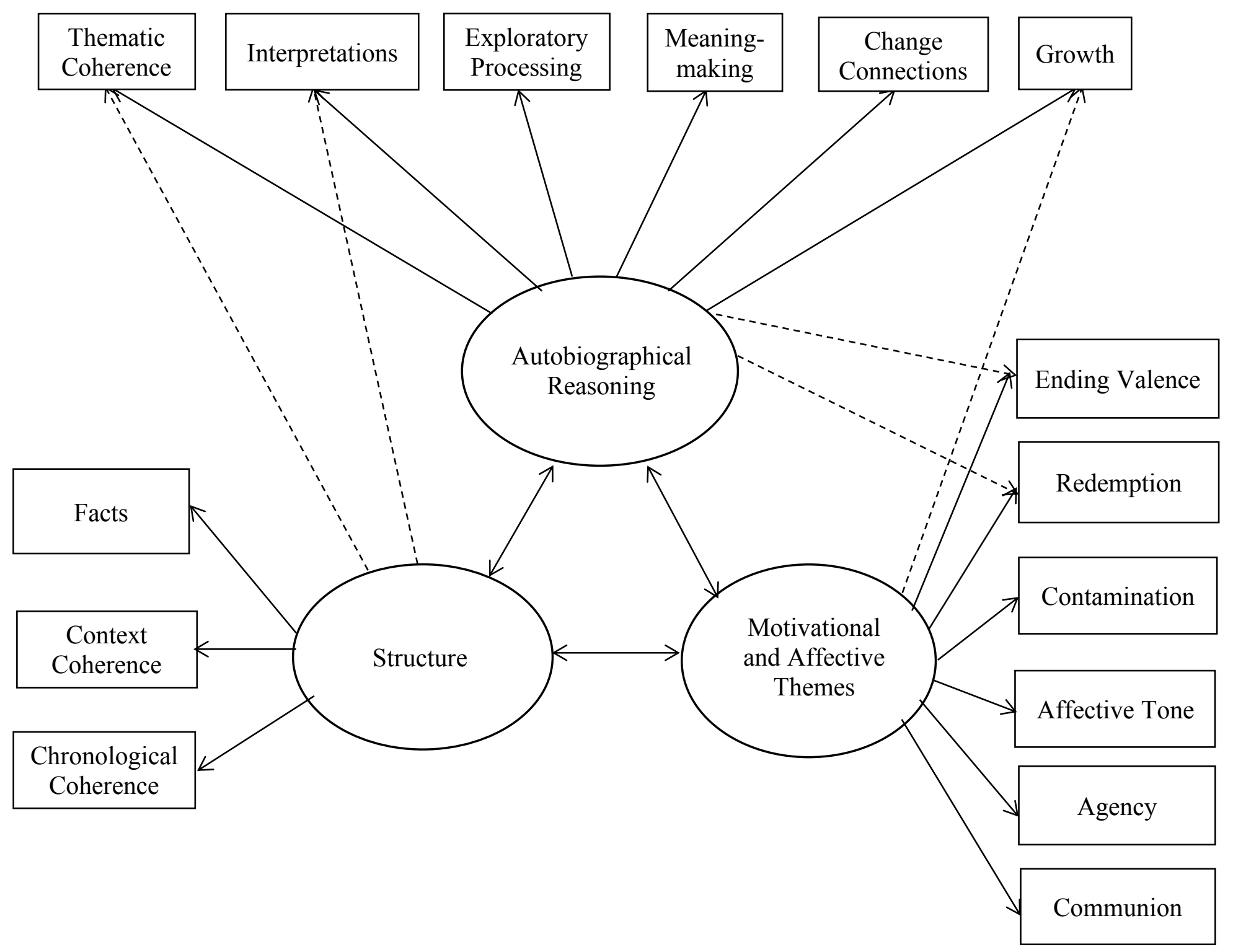

Figure 1. Visual representation of the final Landscape Model. Solid lines indicate primary loadings and dotted lines indicate crossloadings greater than .30 . 


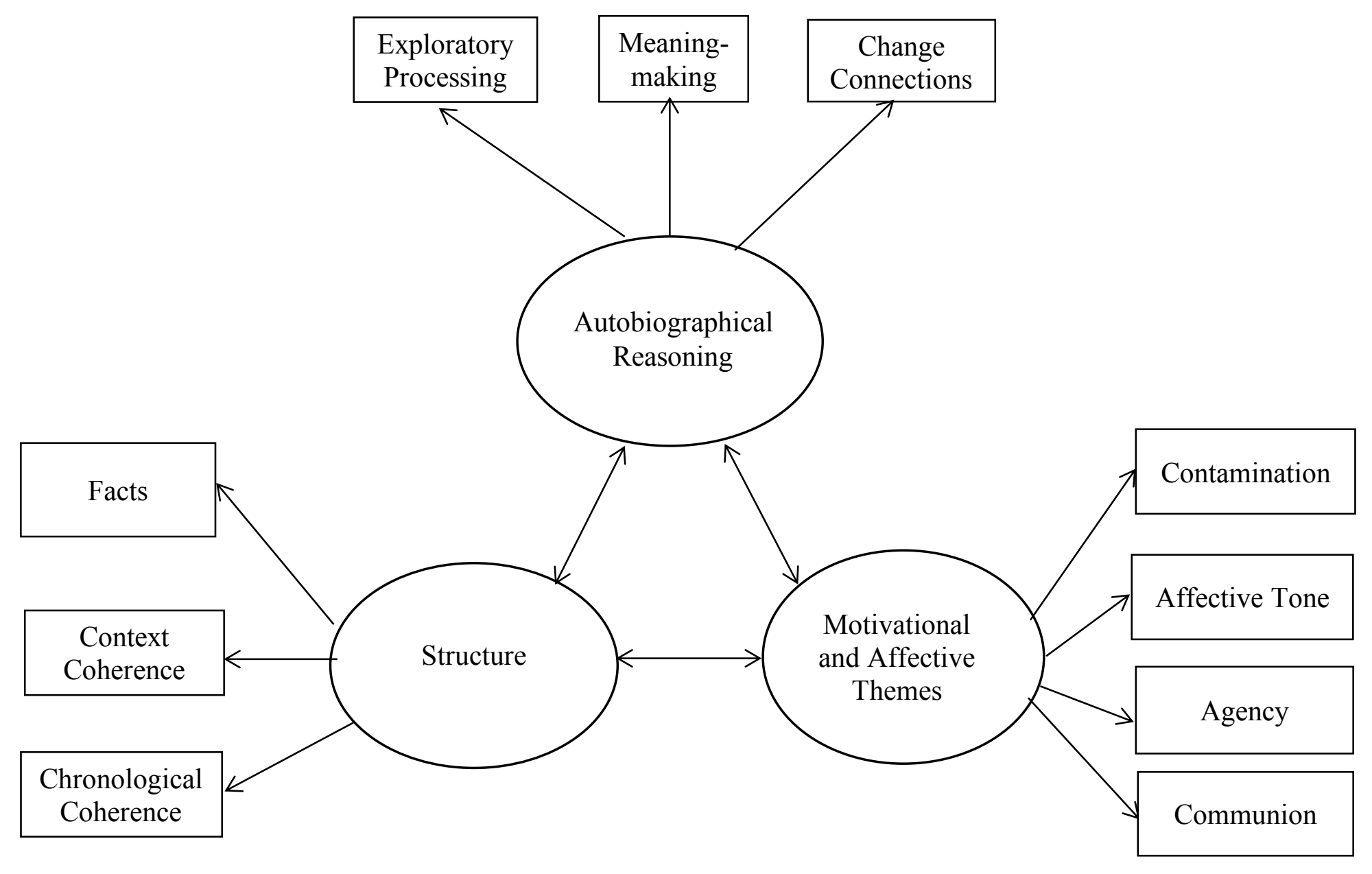

Figure 2. Visual representation of the final Functional Model. 